\title{
A Multiple Piccolino-RIBEYE Interaction Supports Plate-Shaped Synaptic Ribbons in Retinal Neurons
}

\author{
Tanja M. Müller, ${ }^{1 \star}$ (Taspar Gierke, ${ }^{1 \star}$ Anneka Joachimsthaler, ${ }^{2}$-Heinrich Sticht, ${ }^{3}$ ¿Zsuzsanna Izsvák, ${ }^{4}$ \\ F. Kent Hamra, ${ }^{5}{ }^{\circledR}$ Anna Fejtová, ${ }^{6}{ }^{\circ}$ Frauke Ackermann, ${ }^{7}{ }^{\circledR}$ Craig C. Garner, ${ }^{7}{ }^{-}$Jan Kremers, ${ }^{2}{ }^{-}$Johann H. Brandstätter, ${ }^{1}$ \\ and $\odot$ Hanna Regus-Leidig ${ }^{1}$ \\ ${ }^{1}$ Department of Biology, Animal Physiology, FAU Erlangen-Nürnberg, 91058 Erlangen, Germany, ${ }^{2}$ Department of Ophthalmology, University Hospital \\ Erlangen, 91054 Erlangen, Germany, ${ }^{3}$ Institute for Biochemistry, Division of Bioinformatics, FAU Erlangen-Nürnberg, 91054 Erlangen, Germany, \\ ${ }^{4}$ Max-Delbrück Center for Molecular Medicine in the Helmholtz Society, 13125 Berlin, Germany, ${ }^{5}$ Department of Obstetrics and Gynecology, University of \\ Texas Southwestern, Dallas, Texas 75390-9041, ${ }^{6}$ Department of Psychiatry and Psychotherapy, University Hospital Erlangen, 91054 Erlangen, Germany, \\ and ${ }^{7}$ German Center for Neurodegenerative Diseases, 10117 Berlin, Germany
}

Active zones at chemical synapses are highly specialized sites for the regulated release of neurotransmitters. Despite a high degree of active zone protein conservation in vertebrates, every type of chemical synapse expresses a given set of protein isoforms and splice variants adapted to the demands on neurotransmitter release. So far, we know little about how specific active zone proteins contribute to the structural and functional diversity of active zones. In this study, we explored the nanodomain organization of ribbon-type active zones by addressing the significance of Piccolino, the ribbon synapse-specific splice variant of Piccolo, for shaping the ribbon structure. We followed up on previous results, which indicated that rod photoreceptor synaptic ribbons lose their structural integrity in a knockdown of Piccolino. Here, we demonstrate an interaction between Piccolino and the major ribbon component RIBEYE that supports plate-shaped synaptic ribbons in retinal neurons. In a detailed ultrastructural analysis of three different types of retinal ribbon synapses in Piccolo/Piccolino-deficient male and female rats, we show that the absence of Piccolino destabilizes the superstructure of plate-shaped synaptic ribbons, although with variable manifestation in the cell types examined. Our analysis illustrates how the expression of a specific active zone protein splice variant (e.g., Piccolino) contributes to structural diversity of vertebrate active zones.

Key words: ribbon synapse; photoreceptor; active zone; Piccolino; RIBEYE

Significance Statement

Retinal ribbon synapses are a specialized type of chemical synapse adapted for the regulated fast and tonic release of neurotransmitter. The hallmark of retinal ribbon synapses is the plate-shaped synaptic ribbon, which extends from the release site into the terminals' cytoplasm and tethers hundreds of synaptic vesicles. Here, we show that Piccolino, the synaptic ribbon specific splice variant of Piccolo, interacts with RIBEYE, the main component of synaptic ribbons. This interaction occurs via several PxDLS-like motifs located at the $\mathrm{C}$ terminus of Piccolino, which can connect multiple RIBEYE molecules. Loss of Piccolino disrupts the characteristic plate-shaped structure of synaptic ribbons, indicating a role of Piccolino in synaptic ribbon assembly.

\section{Introduction}

Chemical synapses convey information from one neuron to another via regulated exocytosis of neurotransmitter-filled synaptic

Received Aug. 9, 2018; revised Jan. 8, 2019; accepted Jan. 8, 2019.

Author contributions: T.M.M., K.G., and H.R.-L. wrote the first draft of the paper; A.F., C.C.G., J.K., J.H.B., and H.R.-L. edited the paper; J.H.B. and H.R.-L. designed research; T.M.M., K.G., A.J., H.S., and H.R.-L. performed research;Z.I., F.K.H., A.F., F.A., and C.C.G. contributed unpublished reagents/analytic tools; T.M.M., K.G., A.J., H.S., J.K., and H.R.-L. analyzed data; A.J., H.S., and H.R.-L. wrote the paper.

This work was supported by Deutsche Forschungsgemeinschaft Grant RE 3143/2-1 to H.R.-L. and Grant SFB958 to C.C.G., and the Deutsches Zentrum für Neurodegenerative Erkrankungen. We thank Nadja Gießl, Andrea Nerz, and Katja Pertschy for excellent technical assistance, and C. Söldner for help with preparation of Figure 5.

The authors declare no competing financial interests. vesicles (SVs) at the presynaptic active zone (AZ). In the last couple of years, it has become clear that every type of chemical synapse is equipped with a specific set of AZ protein isoforms and splice variants. To understand the functional and structural diversity that follows from the differential expression of AZ components, we need to gain deeper insight into the nanodomain organization of AZs (Ackermann et al., 2015). One of the highly

\section{*T.M.M. and K.G. contributed equally to this work.}

Correspondence should be addressed to Hanna Regus-Leidig at hanna.regus-leidig@fau.de or Johann H. Brandstätter at johann.helmut.brandstaetter@fau.de.

https://doi.org/10.1523/JNEUROSCI.2038-18.2019

Copyright $\odot 2019$ the authors 
conserved AZ components is the large ( $>500 \mathrm{kDa})$ scaffold protein Piccolo, which organizes various aspects of presynaptic function at chemical synapses (Cases-Langhoff et al., 1996; Wang et al., 1999; Gundelfinger et al., 2016). Among these are functions in AZ assembly during synaptogenesis (Shapira et al., 2003), the dynamic regulation of presynaptic actin (Waites et al., 2011; Wagh et al., 2015), the control of presynaptic proteostasis (Waites et al., 2013; Ivanova et al., 2016), the regulation of activity-dependent communication between the presynapse and the nucleus (Ivanova et al., 2015), and the organization of the readily releasable pool of SVs (Butola et al., 2017; Parthier et al., 2018). Piccolo possesses regions of high sequence similarity to Bassoon, another conserved AZ protein. Both proteins share numerous interaction partners, and it is not surprising that the loss of either Piccolo or Bassoon can be largely compensated by the other (Fenster et al., 2000; Mukherjee et al., 2010; Gundelfinger et al., 2016).

However, Piccolo and Bassoon perform also specialized functions that become particularly evident in tonically releasing sensory synapses (e.g., retinal photoreceptors or cochlear inner hair cells). The structural hallmark of these synapses is a proteinaceous organelle at the $A Z$, the synaptic ribbon (SR), to which hundreds of releasable SVs are tethered. It is assumed that the SR evolved as a structural adaptation to the high release rates of sensory neurons (Matthews and Fuchs, 2010; Regus-Leidig and Brandstätter, 2012; Lagnado and Schmitz, 2015). In ribbon synapses, lack of Bassoon leads to free-floating SRs in the cytoplasm and mislocalized and fewer $\mathrm{Ca}^{2+}$ channels, a phenotype that cannot be compensated by Piccolo (Dick et al., 2003; Khimich et al., 2005; Frank et al., 2010). The role of Piccolo at ribbon synapses is less well understood. We recently showed that full-length Piccolo is virtually absent from ribbon synapses, and instead these synapses predominantly express Piccolino, a C-terminally truncated, $\sim 330 \mathrm{kDa}$ Piccolo splice variant (Regus-Leidig et al., 2013). Piccolino, which colocalizes with the major ribbon component RIBEYE at SRs, lacks interaction sites for several conserved AZ proteins (e.g., Bassoon, Munc13, and RIMs) (Schmitz et al., 2000; Regus-Leidig et al., 2013). Knockdown of Piccolino in rod photoreceptors disassembled the plate-shaped SR into multiple aggregates, suggesting a role of Piccolino in the maintenance of SR architecture (Regus-Leidig et al., 2014). In the present study, we analyzed the underlying molecular mechanisms of the scaffolding function of Piccolino at retinal ribbon synapses, taking advantage of a recently generated Piccolo gene trap rat model (Medrano et al., 2018).

\section{Materials and Methods}

Animals. For this study, E18 Sprague Dawley rats, adult (2-4 months) C57BL/6J mice, and adult (2-4 months) Pclo gene trap rats (Pclo ${ }^{\mathrm{gt} / \mathrm{gt}}$ ) were used. A detailed description of how the Pclo ${ }^{\mathrm{gt} / \mathrm{gt}}$ rat strain was generated has been submitted for publication (Medrano et al., 2018). Briefly, transposon mutagenesis resulted in the integration of a transposon element into exon 3 of the PCLO gene, leading to a stop in the reading frame. In experiments comparing Pclo ${ }^{\text {gt/gt }}$ rats with WT rats $\left(\mathrm{Pclo}^{\mathrm{wt} / \mathrm{wt}}\right), \mathrm{Pclo}^{\mathrm{wt} / \mathrm{wt}}$ rats were littermate controls from heterozygous breeding. For each set of experiments, $\mathrm{Pclo}^{\mathrm{wt} / \mathrm{wt}}$ and $\mathrm{Pclo}{ }^{\mathrm{gt} / \mathrm{gt}}$ rats were handled equally and killed in the morning. All animals were maintained on a 12/12 h light/dark cycle with light on at 6:00 A.M. and with food and water ad libitum. Mouse and rat breeding was performed in the animal facilities of the FAU University of Erlangen-Nürnberg according to European and German guidelines for the welfare of experimental animals (AZ 820-8791.2.63). All experiments were performed in compliance with the guidelines for the welfare of experimental animals issued by the Federal Government of Germany and the FAU Erlangen-Nürnberg as well as the animal welfare committee of Charité Medical University and the Berlin state government.

Genotyping. Ear pieces taken from rats were digested overnight at $50^{\circ} \mathrm{C}$ in SNET-buffer ( $400 \mathrm{~mm} \mathrm{NaCl}, 1 \%$ SDS, $200 \mathrm{~mm}$ Tris, pH 8.0, $5 \mathrm{~mm}$ EDTA) containing $10 \mathrm{mg} / \mathrm{ml}$ proteinase $\mathrm{K}$. Subsequently, samples were incubated for $10 \mathrm{~min}$ at $99^{\circ} \mathrm{C}$ and centrifuged for $2 \mathrm{~min}$ at 13,000 rpm. DNA was precipitated from the supernatant with $100 \%$ isopropanol, centrifuged for $15 \mathrm{~min}$ at 13,000 rpm, washed with $70 \%$ ethanol, and centrifuged again for $10 \mathrm{~min}$ at $13,000 \mathrm{rpm}$. The obtained pellet was resuspended in $\mathrm{H}_{2} \mathrm{O}$. PCR with a specific primer combination was performed to determine genotypes. The following primers were used: F2, $5^{\prime}$ GCAGGAACACAAACCAACAA 3'; R1, 5' TGACCTTTAGCCGGAA CTGT 3'; SBF2, 5' TCATCAAGGAAACCCTGGAC 3'. The PCR protocol was the following: 2 min $94^{\circ} \mathrm{C} ; 3 \times\left(30 \mathrm{~s} 94^{\circ} \mathrm{C}, 60^{\circ} \mathrm{C} 30 \mathrm{~s}, 72^{\circ} \mathrm{C} 30 \mathrm{~s}\right)$; $35 \times\left(94^{\circ} \mathrm{C} 30 \mathrm{~s}, 55^{\circ} \mathrm{C} 30 \mathrm{~s}, 72^{\circ} \mathrm{C} 30 \mathrm{~s}\right) ; 72^{\circ} \mathrm{C} 10 \mathrm{~min}$.

Antibodies. The following primary antibodies were used for immunocytochemistry (ICC), immunoelectron microscopy (EM), and Western blotting (WB): monoclonal mouse anti-Bassoon (ICC 1:2500; Stressgen), mouse anti-CtBP1 (ICC 1:10,000; WB 1:5000; BD Biosciences), mouse anti-CtBP2/RIBEYE (ICC 1:20,000; WB 1:5000; BD Biosciences), mouse anti-Grp75 (ICC 1:400; Abcam), mouse anti-KIF3A (ICC 1:500, WB 1:1000; Covance, BioLegend), mouse anti-Pclo (ICC 1:5000; Synaptic Systems), polyclonal goat anti-GST (WB 1:20,000; GE Healthcare), polyclonal rabbit anti-Ca 1.4 (ICC 1:3000) (Specht et al., 2009), rabbit anti-CtBP2 (ICC 1:10,000; Synaptic Systems), rabbit anti-GFP (WB 1:2000; Thermo Fisher Scientific), rat anti-LAMP1 (ICC 1:500; Santa Cruz Biotechnology), rabbit anti-Pclo4 (ICC 1:5000; WB 1:1000) (Regus-Leidig et al., 2013), guinea pig anti-Pclo (ICC 1:5000; Synaptic Systems), rabbit anti-Pclo49 (ICC 1:5000) (Regus-Leidig et al., 2013), rabbit anti-RIBEYE A (ICC/EM 1:50,000, WB 1:1000; Synaptic Systems), and rabbit anti-ubMunc13-2 (ICC 1:6000) (Cooper et al., 2012). Nuclei were stained with DAPI (1:50,000; Sigma-Aldrich). The following secondary antibodies were used: Alexa-488/594-conjugated goat antimouse and goat anti-rabbit IgG (1:250-1:500; Invitrogen), Cy3/Cy5conjugated goat anti-mouse and goat anti-rabbit $\operatorname{IgG}(1: 100-1: 200$; Dianova, Jackson ImmunoResearch Laboratories), HRP-conjugated goat anti-mouse/rabbit IgG (1:10,000; Sigma-Aldrich), and HRPconjugated mouse anti-goat IgG (1:10,000; Santa Cruz Biotechnology).

Light microscopic immunocytochemistry. Preparation of retinal tissue and antibody incubation for light microscopic immunocytochemistry was performed as described previously (Dick et al., 2001). Briefly, the eyes were opened, and retinae were immersion fixed in the eyecup for 15 min in $4 \%$ PFA in PB (0.1 M, pH 7.4). Retinae were mounted in freezing medium (Reichert-Jung), and $12-\mu \mathrm{m}$-thick vertical sections were cut with a cryostat (CM3050 S, Leica Microsystems). Primary antibody incubation was performed overnight at room temperature, secondary antibody incubation for $1 \mathrm{~h}$. For analysis, labeled sections were examined with an Axio Imager Z1 equipped with an ApoTome (Carl Zeiss). Images were taken with a $20 \times(0.8$, Apochromat $), 63 \times(1.4$ oil, Apochromat), or a $100 \times$ (1.3 oil, Plan-Neofluar) objective as stacks of multiple optical sections, and projections were calculated with the ZEN software (Carl Zeiss). Images were adjusted for contrast and brightness using Photoshop CS (Adobe). To quantify the number of cell rows in the outer nuclear layer, two different DAPI-stained retina sections/animal from 3 $\mathrm{Pclo}^{\mathrm{wt} / \mathrm{wt}}$ and $3 \mathrm{Pclo}^{\mathrm{gt} / \mathrm{gt}}$ rats were analyzed. For retina whole-mount stainings, fixed retinae were subjected to four cycles of freezing in liquid nitrogen and thawing at $37^{\circ} \mathrm{C}$ before antibody incubation. Primary antibody incubation was performed for $5 \mathrm{~d}$ at $4^{\circ} \mathrm{C}$, secondary antibody incubation for $2 \mathrm{~h}$ at room temperature. Lateral extensions of SRs $(\alpha-$ RIBEYE) and AZs ( $\alpha$-Bassoon) were measured with the ZEN software (Carl Zeiss).

Coimmunoprecipitation. Retinae were homogenized in $1 \mathrm{ml}$ extraction buffer (100 mm Tris-HCl, pH 8.0, $150 \mathrm{~mm} \mathrm{NaCl,} \mathrm{1 \%} \mathrm{Triton} \mathrm{X-100)} \mathrm{per}$ animal. Insoluble material was pelleted. For antibody immobilization, protein A Mag Sepharose beads ( $25 \mu \mathrm{l}$ bed volume; GE Healthcare) were incubated overhead for $1 \mathrm{~h}$ with $10 \mu \mathrm{g}$ of antibody (Pclo4; $\alpha$-GFP served as control). The extract corresponding to two retinae was applied overnight to the antibody-coupled beads. Bound proteins were eluted after extensive washes in extraction buffer by boiling in sample buffer. Ex- 
tracted material (input) and unbound proteins in the supernatant were concentrated by TCA precipitation before boiling in sample buffer.

Western blot analysis. Retinal tissue was homogenized in lysis buffer (320 mM saccharose, $4 \mathrm{~mm}$ HEPES, pH 7.5) and centrifuged at $1000 \times g$ for $10 \mathrm{~min}$. The supernatant (S1) was centrifuged at $20,000 \times g$ for 20 min. Pellets (P2) were dissolved in SDS-sample buffer. Proteins were separated by SDS-PAGE using NuPAGE Novex 3.5\%-8\% Tris acetate gels (Thermo Fisher Scientific) or self-made 5\% polyacrylamide gels (20 $\mu \mathrm{g} /$ lane), and transferred to PVDF membranes (Immobilon-P, Merck Millipore) by semidry or tank blotting (Trans-Blot Turbo/Cell, Bio-Rad Laboratories). For immunodetection, membranes were blocked with skimmed milk powder or blocking solution (10 mM Tris, $150 \mathrm{~mm} \mathrm{NaCl}$, $0.2 \%$ blocking reagent; AppliChem), and primary antibodies were applied overnight at $4^{\circ} \mathrm{C}$. HRP-conjugated secondary antibodies were visualized by chemiluminescent detection (Luminata Forte, Millipore). Images were obtained with a molecular imager (ChemiDoc XRS, BioRad Laboratories) and adjusted for contrast and brightness using Photoshop CS (Adobe).

Vector generation. The following Piccolo [Pclo-201: ENSMUST00000030691] and RIBEYE fragments [CtBP2-214: ENSMUST00000169570.7] were PCR-amplified from C57BL/6J mouse retina cDNA: mp11 (aa 1-241), mp12 (aa 228-412), mp21 (aa 407-737), mp22 (aa 733-1315), mp31 (aa 1311-1561), mp32 (aa 1557-1909), mp41 (aa 1905-2220), mp42 (aa 2216-2571), RIBEYE A domain: RIB(A) (aa 1-565), and RIBEYE B domain: RIB(B) (aa 560-988). The C-terminal Piccolino-specific fragment mp5 (aa 2567-2984) carrying the first 22 aa of PCLO intron5/6 was amplified from C57BL/6J mouse genomic DNA. The PCR products were subcloned into the $\mathrm{pCR} 8 / \mathrm{GW} /$ TOPO vector (Thermo Fisher Scientific) via TA cloning. The smaller fragments mp51 (aa 2567-2724), mp52 (aa 2718-2795), mp53 (aa 2790-2839), mp54 (aa 2835-2922), mp55 (aa 2917-2984), and mp56 (aa 2835-2984) were amplified using the mp5 plasmid as a template. For generation of full-length RIBEYE and the fragments mp1 (aa 1-412), mp2 (aa 407-1315), mp3 (aa 1311-1909), and mp4 (aa 1905-2571), the smaller fragments were fused together via seamless cloning according to the manufacturer's instructions (Thermo Fisher Scientific). Full-length Piccolino was generated by GenBrick synthesis (GeneScript) and subcloned into the $\mathrm{pCR} 8 / \mathrm{GW} / \mathrm{TOPO}$ vector.

Expression vectors containing eYFP-tagged Piccolo fragments were generated by subcloning the corresponding fragment into the destination vector eYFP/Dest N-Term Erl.5.6 via LR reaction (Thermo Fisher Scientific). Full-length RIBEYE, RIB(A) and RIB(B) were subcloned into the destination vector pDest-mCherry-N-term- pcDNA3.1hygro. In addition, $\mathrm{RIB}(\mathrm{A})$ and $\mathrm{RIB}(\mathrm{B})$ were subcloned into the destination vector pDest-Mito-human-N-term-pcDNA3.1hygro. The latter two destination vectors were kindly provided by Dr. A. Gießl (Department of Biology, Animal Physiology, FAU Erlangen-Nürnberg, Erlangen, Germany). For generation of untagged and GST-tagged proteins, full-length RIBEYE, RIB(A) and RIB(B), mp5 and full-length Piccolino were subcloned into the destination vector pcDNA3native/Dest (Dr. A. Gießl) and/or pDest 27 (Thermo Fisher Scientific). Vectors expressing mutated RIBEYE or mp5 were amplified by PCR from the respective pCR8/GW/ TOPO vector using the following oligonucleotides: RIBEYE ${ }^{\triangle P x D L S-B C}$ $($ Ala601 $\rightarrow$ Glu and Val615 $\rightarrow$ Arg): 5' CCACTGTGGAGTTCTGTGATG CACAGTCCACTCAGGAAATCCATGAGAAGCGGTTGAATGAGG 3'; $\mathrm{mp5}^{\mathrm{DL} \rightarrow \mathrm{AS}}($ Asp2860 $\rightarrow$ Ala and Leu2861 $\rightarrow$ Ser $): 5^{\prime}$ GAAAAGC CAGTTGCTTCGACTGCAGGAAGACGAGCTG $3^{\prime}$ and mp5 $5^{\text {RGASI }}$ (Pro2858 $\rightarrow$ Arg, Val2859 $\rightarrow$ Gly, Asp2860 $\rightarrow$ Ala, Leu2861 $\rightarrow$ Ser and Thr2862 $\rightarrow$ Ile): $5^{\prime}$ GAAAAGCGAGGTGCTTCGATTGCAGGAAGAC GAGCTG 3'. All constructs were verified by sequencing.

GST pulldown assay. At $72 \mathrm{~h}$ after transfection, HEK293T cells were lysed in lysis buffer (50 mm Tris-HCl, pH 7.5, 5 mм EDTA, $150 \mathrm{~mm} \mathrm{NaCl}$, $1 \%$ Triton X-100), samples were sonicated and centrifuged at 20,000 $\times g$ for $15 \mathrm{~min}$. Supernatants containing the GST fusion proteins were diluted 1:1 in HNTG buffer (10\% glycerol, 20 mm HEPES, $120 \mathrm{~mm} \mathrm{NaCl}$, $0.3 \%$ Triton X-100, $1 \mathrm{~mm} \mathrm{CaCl}_{2}, 1 \mu \mathrm{M} \beta$-mercaptoethanol, $\mathrm{pH}$ 7.3) before loading onto glutathione Sepharose $4 \mathrm{~B}$ beads (GE Healthcare). After a $3 \mathrm{~h}$ incubation step in an overhead shaker at $4^{\circ} \mathrm{C}$, the beads were washed three times in HNTG buffer. Subsequently, cell lysates contain- ing the prey protein were added to the beads and incubated overnight in an overhead shaker at $4^{\circ} \mathrm{C}$. Pulldowns were washed three times in HNTG buffer before elution in sample buffer at $95^{\circ} \mathrm{C}$ for $5 \mathrm{~min}$. SDS-PAGE, Western blotting, and immunodetection were performed as described above.

Cell culture and transfection. NIH 3T3 and HEK293T cells were transfected with polyethylenimine according to the manufacturer's instructions (Polysciences). Cells were fixed $24 \mathrm{~h}$ after transfection for $10 \mathrm{~min}$ in $4 \% \mathrm{PFA}$ in $\mathrm{PB}$ and subjected to immunocytochemistry as described above.

Protein modeling. The RIBEYE B domain is identical in sequence to the corepressor C-terminal Binding Protein (CtBP), for which the 3D structure is known. For modeling of higher-order RIBEYE-B oligomers, the structure of dimeric rat CtBP (PDB: 1HL3) (Nardini et al., 2003) was used because it contains two cocrystallized PxDLS ligands. Rat and human CtBP exhibit $87 \%$ sequence identity and share a highly similar 3D structure. To obtain regular geometric arrangements, oligomer modeling was performed by in-plane translation of the individual dimers using SwissModel (Guex and Peitsch, 1997). Chimera (Pettersen et al., 2004) was used for structure analysis and visualization.

Electron microscopy. For conventional electron microscopy, retinae were fixed in $4 \%$ PFA and $2.5 \%$ glutaraldehyde for $2 \mathrm{~h}$ at room temperature, followed by incubation in $2 \%$ osmiumtetroxide for $1.5 \mathrm{~h}$. After dehydration in rising EtOH concentrations (30\%-100\%) and propylenoxide retinae were embedded in Epon resin. For analysis, semithin sections and (serial) ultrathin sections were cut with an Ultracut E microtome (Reichert-Jung). Finally, samples were contrasted with lead citrate and uranyl acetate in an automatic contrasting system (EM AC20, Leica Microsystems). Ultrathin sections were examined and photographed with an EM10 electron microscope (Carl Zeiss) equipped with a SC1000 OriusTM CCD camera (GATAN) in combination with the DigitalMicrograph 3.1 software (GATAN). The 3D reconstructions from $\sim 55 \mathrm{~nm}$ ultrathin serial sections were generated with reconstruct version 1.1.0.1 software (J. Fiala, Medical College of Georgia). Dimensions of reconstructed SRs were measured using iMOD software (3dmod version 4.9.4 by James Kremer and David Mastronarde, ( $1994-2017$ by the Regents of the University of Colorado). SR length was measured from end to end of the ribbon material along the active zone. Mean SR heights were determined by measuring the perpendicular extension of the SR into the cytosol at five different positions for each individual ribbon.

For pre-embedding immunoelectron microscopy, retinae were prefixed in 4\% PFA in PBS for 50 min at room temperature and further processed as described previously (Regus-Leidig et al., 2013; Fuchs et al., 2014). Briefly, after four freeze and thaw cycles, retinae were washed in PBS and embedded in PBS buffered 2\% agar. Agar blocks were sectioned into $70 \mu \mathrm{m}$ sections with a vibratome VT 1000 S (Leica Microsystems). Subsequently, sections were incubated in $10 \%$ normal goat serum, $1 \%$ BSA in PBS for $2 \mathrm{~h}$, followed by incubation with primary antibodies for $4 \mathrm{~d}$ at $4^{\circ} \mathrm{C}$. PBS washed sections were incubated with biotinylated secondary antibodies (1:500) and visualized by Vectastain ABC-Kit (both from Vector Laboratories). The sections were postfixed in $2.5 \%$ glutaraldehyde in cacodylate buffer. Diaminobenzidine precipitates were silver enhanced and postfixed in $0.5 \% \mathrm{OsO}_{4}$ in cacodylate buffer for $30 \mathrm{~min}$ at $4^{\circ} \mathrm{C}$. Dehydrated specimens were flat-mounted between ACLAR-films (Ted Pella) in Epon resin (Fluka) and polymerized at $60^{\circ} \mathrm{C}$ for at least $18 \mathrm{~h}$.

Electroretinographic (ERG) recordings. The animals were dark-adapted overnight for ERG measurements. All further handling was done under dim red light to maintain rod sensitivity. Animals were anesthetized by an intramuscular injection of $60 \mathrm{mg} / \mathrm{kg}$ ketamine (Ketavet, Pfizer) and 5 $\mathrm{mg} / \mathrm{kg}$ xylazin (Rompun $2 \%$, Bayer). A subcutaneous injection of $0.8 \mathrm{ml}$ saline $(0.9 \%)$ kept the rats hydrated while under sedation. The eyes were additionally locally anesthetized with a drop of oxybuprocainhydrochloride (Conjucain EDO 0.4\%, Dr. Mann Pharma). The pupils were dilated with a drop of tropicamide (Mydriaticum Stulln, $5 \mathrm{mg} / \mathrm{ml}$, Pharma Stulln) and phenylephrine-hydrochloride (Neosynephrin POS 5\%, Ursapharm), each. The animals were then transferred to a heated platform inside the Ganzfeld stimulator (Roland Consult, Q450 SC). Ground and reference needle electrodes were inserted subcutaneously at the tail base 

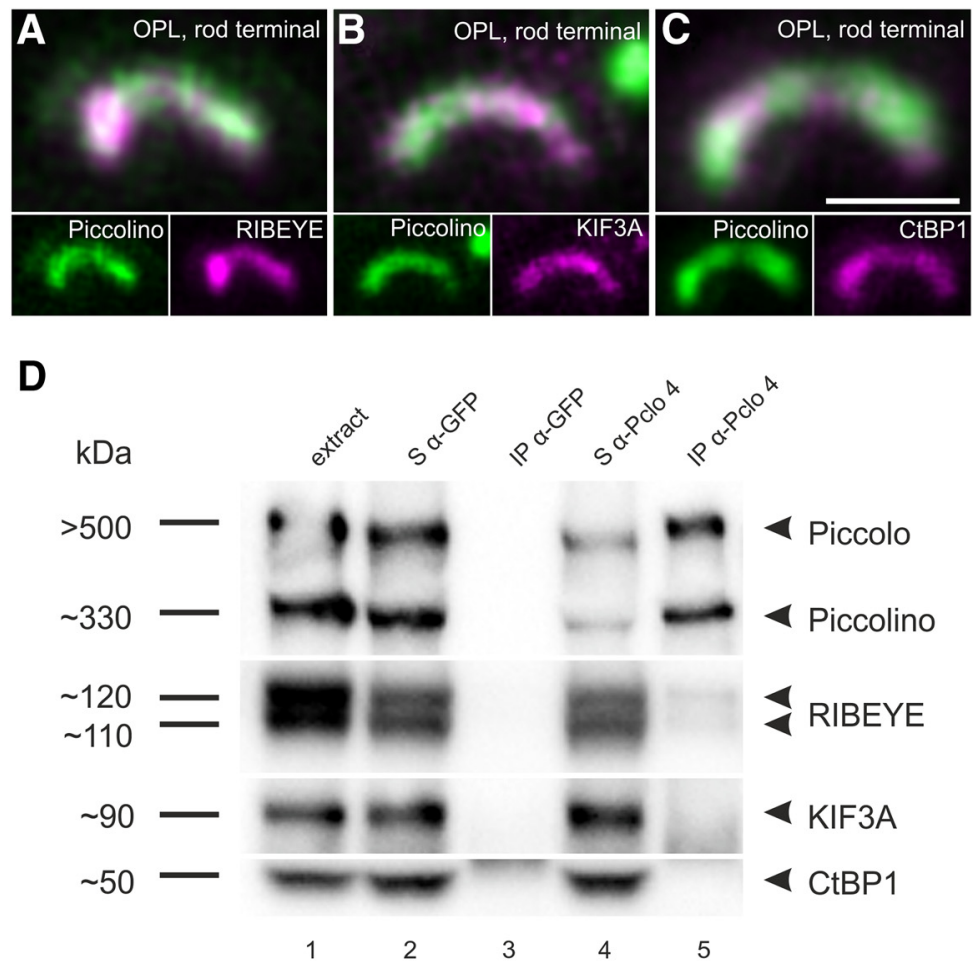

E
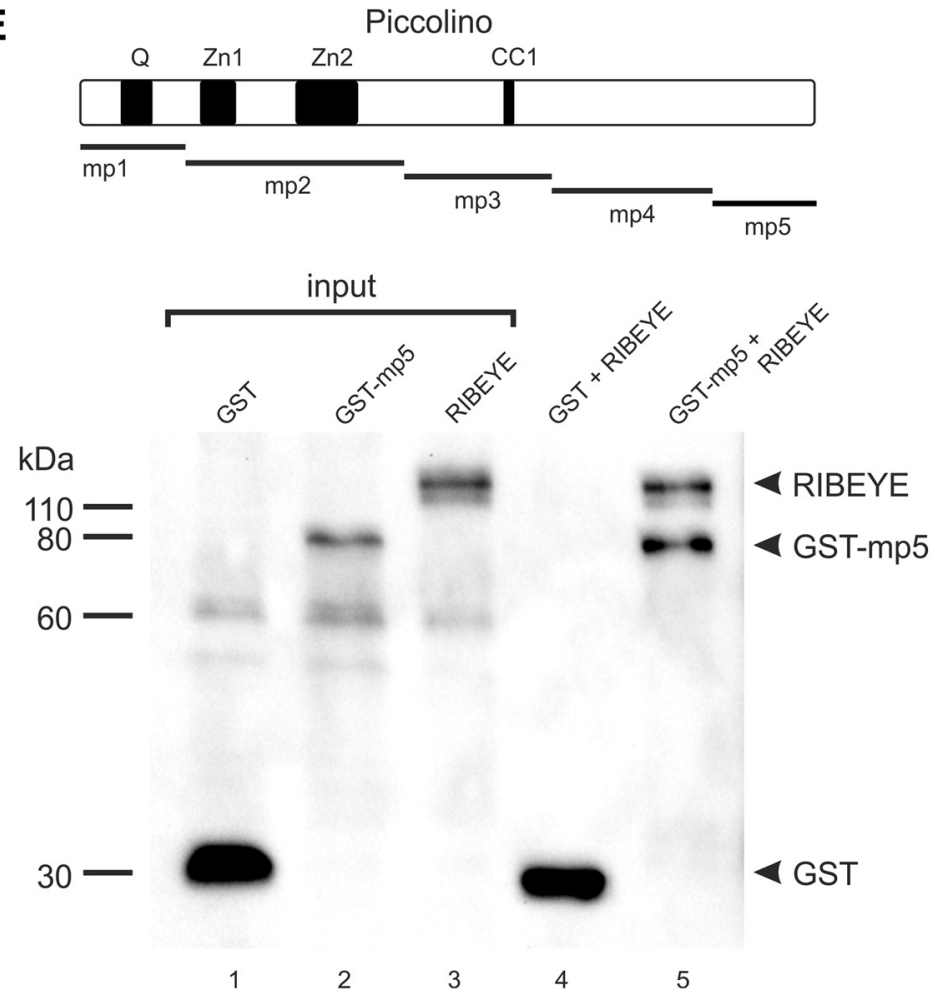

Figure 1. Identification of a Piccolino-RIBEYE interaction. $\boldsymbol{A}-\boldsymbol{C}$, Rod photoreceptor SRs in the OPL of the mouse retina double-labeled for Piccolino (green) and RIBEYE (magenta; $\boldsymbol{A}$ ), KIF3A (magenta; $\boldsymbol{B}$ ), and CtBP1 (magenta; $\boldsymbol{C}$. D D Coimmunoprecipitation experiments from murine retina lysates with the antibody Pclo4, and an antibody against GFP as negative control stained against Piccolo/Piccolino, Bassoon, RIBEYE, KIF3A, and CtBP1. E, GST pulldown assay of GST-tagged Piccolino fragments (mp1-mp5; bait) with full-length RIBEYE (prey). Only GST-mp5 interacted with RIBEYE. GST-tag alone served as control. Samples were analyzed by immunoblotting with antibodies against GST and RIBEYE; $n=4$ individual experiments. CC1, Coiled-coil domain; IP, immunoprecipitate; $\mathrm{mp}$, mouse Piccolino; $Q, Q$ domain; $S$, supernatant; $\mathrm{Zn} 1 / Z n 2$, zinc finger. Scale bar: (in $C) A-C, 1 \mu \mathrm{m}$. and the forehead, respectively. The eyes were hydrated with a drop of Corneregel (Dr. Mann Pharma) and gold ring electrodes ( $\varnothing 5 \mathrm{~mm}$ ), which served as actives, were placed on both eyes. To ensure maximal rod sensitivity, the animals were dark-adapted for another $5 \mathrm{~min}$. Subsequently, a scotopic flash ERG was recorded with increasing flash intensities from -3.7 to $0.8 \log$ phot $\mathrm{cd} \cdot \mathrm{s} / \mathrm{m}^{2}$ (equals -3.5 to $1.0 \log \operatorname{scot} \mathrm{cd} \cdot \mathrm{s} / \mathrm{m}^{2}$ ). Interstimulus intervals increased from 5 to $20 \mathrm{~s}$, depending on the flash strength (24 to 6 flash responses were averaged per stimulus strength) to assay outer retinal function (Frishman, 2006). After a light adaptation to a $1.4 \mathrm{log}$ phot $\mathrm{cd} / \mathrm{m}^{2}$ background (white light) for $5 \mathrm{~min}$, the responses to photopic flashes were recorded to examine conedriven physiology in the outer retina (Frishman, 2006). The stimulus strength increased from -0.2 to $0.8 \log$ phot $\mathrm{cd} \cdot \mathrm{s} / \mathrm{m}^{2}$ (equals 0.0 to $1.0 \log \mathrm{scot} \mathrm{cd}$ $\cdot \mathrm{s} / \mathrm{m}^{2}$; interstimulus interval: $1 \mathrm{~s} ; 30$ averages per flash strength), and the flashes were presented additionally to the background light. In a last protocol, we recorded responses to a photopic, sinusoidalmodulated flicker stimulus at $12,18,24$, and $30 \mathrm{~Hz}$ (1.4 log phot $\mathrm{cd} / \mathrm{m}^{2}$ mean luminance, $100 \% \mathrm{Mi}-$ chelson contrast, $1 \mathrm{~s}$ flicker was averaged 40 times per stimulus frequency). The total duration of ERG measurements was $\sim 45 \mathrm{~min}$.

Visual stimulation and signal acquisition were controlled by the RetiPort system (Roland Consult). ERG signals were amplified 10,000 times, bandpass-filtered $(1-300 \mathrm{~Hz})$, and digitized with a sampling rate of either $2044 \mathrm{~Hz}$ (flash ERGs) or $1023 \mathrm{~Hz}$ (flicker ERG). The data were further analyzed with custom-written MATLAB programs (The MathWorks). The responses of the flash ERGs were Fourier transformed, and the amplitudefrequency spectrum was divided into a lowand high-frequency range by a variable filter to isolate the $\mathrm{a}$ and $\mathrm{b}$ wave from the oscillatory potentials as previously described by Harazny et al. (2009). Afterward, we performed a reverse Fourier transformation on the low-pass frequency range and further analyzed $a$ and $b$ wave in the amplitude versus time plot. Implicit times of the $a$ and $b$ wave were defined as the time difference between the flash and the minimum/maximum of the a-wave trough/bwave peak. The a-wave amplitudes were measured from preflash baseline to trough, and the b-wave amplitude was set as a-wave trough to b-wave peak. The responses to the flicker stimuli were also Fourier transformed, and the amplitude and phase of the first harmonic were extracted for further analyzation.

Experimental design and statistical analysis. For measurements of rod photoreceptor SR length and $\mathrm{AZ}$ extension, $3 \mathrm{Pclo}^{\mathrm{wt} / \mathrm{wt}}$ (both sexes) and 3 Pclo $^{\text {gt/gt }}$ (both sexes) rats were used for whole-mount preparations. The age of the animals ranged from 8 to 12 weeks.

In total, 872 SRs and $855 \mathrm{AZs}$ of Pclo ${ }^{\text {wt/wt }}$ as well as 1104 SRs and 986 AZs of Pclo ${ }^{\text {gt/gt }}$ were analyzed. Statistical differences were tested using unpaired $t$ test. An $\alpha$ value of $p<0.05$ was adopted for statistical significance. Comparison of photoreceptor nuclei rows was per- 

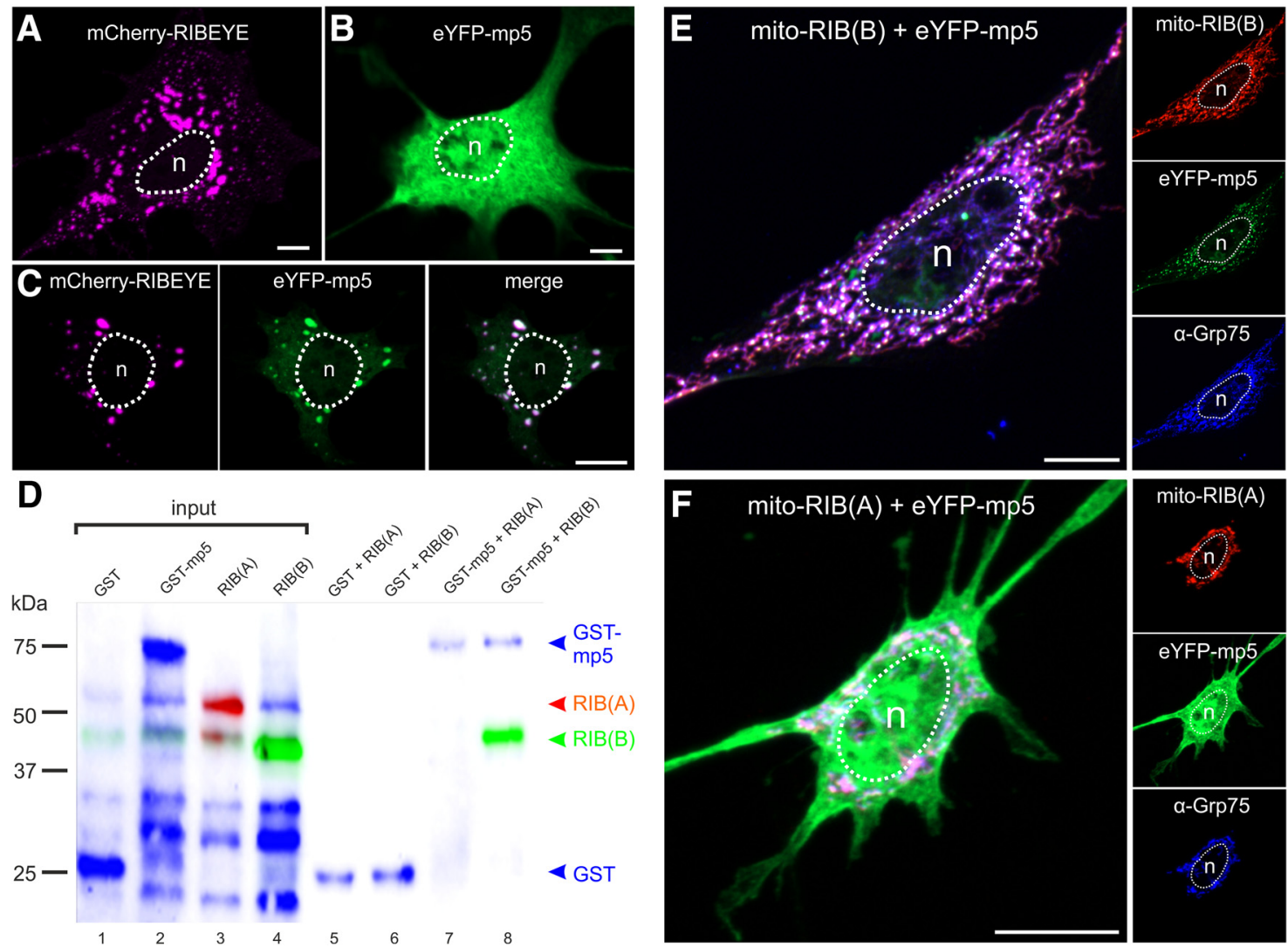

Figure 2. C terminus of Piccolino interacts with RIBEYE B domain. $\boldsymbol{A}, \boldsymbol{B}$, Transfected NIH 3 T3 cells with mCherry-RIBEYE (magenta; $\boldsymbol{A}$ ) or eYFP-mp5 (green; $\boldsymbol{B}$ ); $n=3$ individual experiments. $\boldsymbol{C}$, Cotransfected NIH 3 T3 cells with mCherry-RIBEYE (magenta) and eYFP-mp5 (green); $n=10$ individual experiments. D, GST pulldown assay of GST-mp5 (bait) with RIB(A) or RIB(B) (prey). GST-tag alone served as control. Samples were analyzed by immunoblotting with antibodies against GST (blue), RIBEYE (red), and CtBP2 (green). Image is an overlay with pseudo-colors; $n=3$ individual experiments. $\boldsymbol{E}, \boldsymbol{F}$, Cotransfected NIH $3 \mathrm{~T} 3$ cells with eYFP-mp5 (green) and RIB(B) or RIB(A) fused to a mitochondrial targeting sequence: mito-RIB(B), mito-RIB(A) (both red). Only the mito-RIB(B) fusion protein is able to recruit eYFP-mp5 to the mitochondria of the cell (Grp75, blue); $n=5$ individual experiments. mp, Mouse Piccolino; $\mathrm{n}$, nucleus. Scale bars, $10 \mu \mathrm{m}$.

formed with $3 \mathrm{Pclo}^{\mathrm{wt} / \mathrm{wt}}$ and 3 Pclo ${ }^{\mathrm{gt} / \mathrm{gt}}$ rats. Statistical differences were tested using unpaired $t$ test, and an $\alpha$ value of $p<0.05$ was adopted as the threshold for significance. For ERG recordings, statistical differences between 8 - and 12-week-old Pclo ${ }^{\text {wt/wt }}(n=9$, both sexes $)$ and Pclo ${ }^{\text {gt/gt }}$ rats ( $n=13$, both sexes) were tested using Kruskal-Wallis test as the data could not be described by a normal distribution. An $\alpha$ value of 0.05 was adopted for significance.

\section{Results}

Piccolino interacts with the main ribbon component RIBEYE In our previous study, we knocked down Piccolino in rod photoreceptors and showed that Piccolino deficiency affects SR architecture (Regus-Leidig et al., 2014). To address the underlying molecular mechanism, we searched for direct binding partner(s) of Piccolino at SRs. We restricted our analysis to proteins that have been shown to colocalize with Piccolino at rod photoreceptor SRs (i.e., RIBEYE, KIF3A, and CtBP1) (tom Dieck et al., 2005; Zanazzi and Matthews, 2009; Matthews and Fuchs, 2010) (Fig. $1 A-C)$. We performed coimmunoprecipitation experiments with the previously published Pclo4 antibody (Regus-Leidig et al., 2013, 2014) from murine retina extracts (Fig. 1D). Of the three analyzed proteins, only RIBEYE weakly coimmunoprecipitated with Piccolo/Piccolino, suggesting a Piccolino-RIBEYE interaction (Fig. 1D, lane 5). The weak RIBEYE band may be the result of the stringent buffer conditions needed for this experiment, which may also be the reason why our analysis did not reveal the previously published interaction of Piccolo with CtBP1 (Ivanova et al., 2015). Next, we divided Piccolino into multiple clones [mouse Piccolino (mp)1-mp5], and performed fusion protein pulldown experiments to characterize the PiccolinoRIBEYE interaction in more detail (Fig. 1E). In the pulldown experiments, GST-tagged mp1-mp5 were used as immobilized bait proteins and full-length RIBEYE was used as the soluble prey protein; GST alone served as control protein. While GST-mp5 pulled down RIBEYE (Fig. 1E, lane 5), no other regions of Piccolino seemed to interact with RIBEYE (data not shown).

We further used the ability of RIBEYE to self-aggregate in heterologous expression systems (Schmitz et al., 2000; Magupalli et al., 2008) (Fig. 2A) and tested whether the eYFP-tagged Piccolino fragment mp5 is recruited to RIBEYE aggregates when cotransfected with mCherry-tagged RIBEYE in NIH 3T3 cells. In single transfections, eYFP-mp5 diffusely spread throughout the cell (Fig. 2B). Upon coexpression with mCherry-tagged RIBEYE, eYFP-mp5 changed from a diffuse distribution to almost complete coaggregation with mCherry-RIBEYE (Fig. 2C). To test whether the observed aggregates are simply degradation products, we stained NIH 3T3 cells expressing mCherry-RIBEYE and eYFP-mp5 with the lysosomal marker LAMP1. We did not detect any colocalization of the RIBEYE-mp5 aggregates with the lysosomes (data not shown).

RIBEYE consists of an N-terminal RIBEYE-specific A domain and a C-terminal B domain that is identical to the transcriptional corepressor CtBP2, except for the first 20 amino acids (Schmitz et al., 2000). We divided RIBEYE into its two domains and tested them in fusion protein pulldown experiments to identify which 

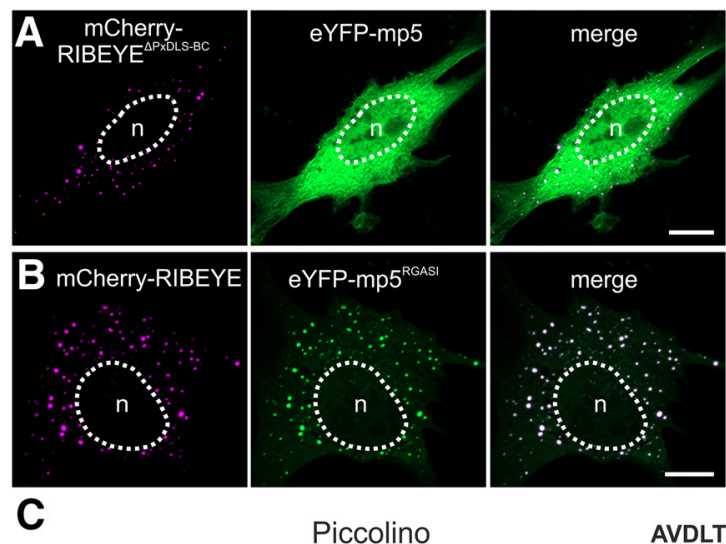

D
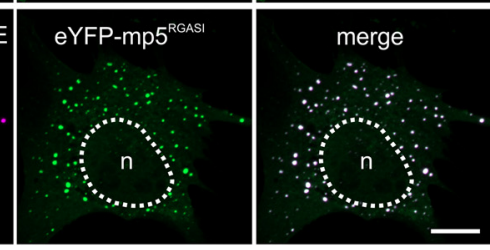

C

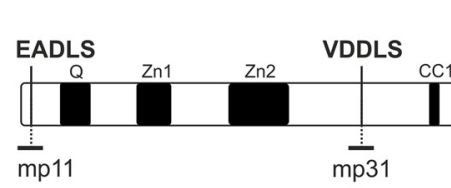

Piccolino

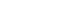
.

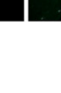

(1)

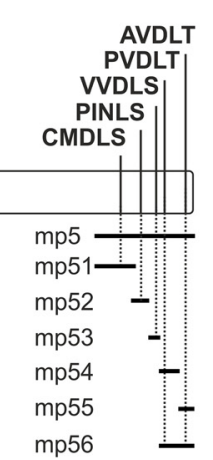

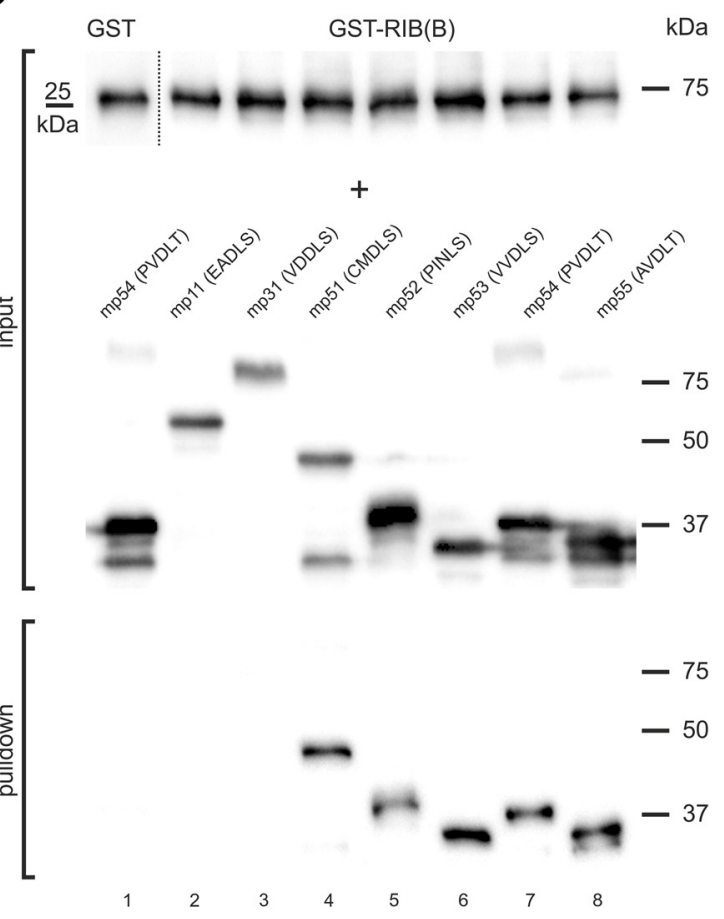

Figure 3. Piccolino interacts with RIBEYE via multiple PxDLS-like motifs. $\boldsymbol{A}$, Cotransfected NIH 3 T3 cells with eYFP-mp5 (green) and mCherry-RIBEYE with mutated PxDLS binding cleft $\left(\right.$ Ala601 $\rightarrow$ Glu and Val615 $\rightarrow$ Arg; $m$ Cherry-RIBEYE ${ }^{\Delta \text { PxDLS-BC }}$, magenta); $n=3$ individual experiments. B, Cotransfected NIH 3 T3 3 cells with eYFP-mp5 with mutated PVDLT-motif (PVDLT $\rightarrow$ RGASI; $\mathrm{mp} 5^{\text {RGASI}}$, green) and mCherry-RIBEYE (magenta); $n=3$ individual experiments. C, Schematic representation of Piccolino with seven identified potential PxDLS-like motifs. D, GST pulldown assays of GST-tagged RIB(B) (bait) with the different, single-PxDLS-like motif containing Piccolino fragments (mp11, mp31, mp51-56). The five C-terminally located PxDLS-like motifs interact with RIB(B); $n=3$ individual experiments. CC1, Coiled-coil domain; mp, mouse Piccolino; $n$, nucleus; $Q, Q$ domain; Zn1/Zn2, zinc finger. Scale bars: $A, B, 10 \mu \mathrm{m}$.

of the two domains conveys Piccolino binding (Fig. 2D). Our analysis revealed an interaction of $\mathrm{mp} 5$ with the $\mathrm{B}$ domain, but not with the A domain, of RIBEYE (Fig. 2D, lanes 7 and 8). We confirmed this interaction with the corecruitment assay in NIH 3T3 cells (Fig. 2E,F). As RIBEYE only forms aggregates when expressed as full-length protein, we expressed both RIBEYE A and RIBEYE $\mathrm{B}$ domains fused to a mitochondrial targeting sequence [mito-RIB(A) and mito-RIB(B)] to target each RIBEYE domain to the mitochondria of transfected cells (Fig. 2E, F, red). The correct mitochondrial localization was confirmed by counterstaining with the mitochondrial marker Grp75 (Fig. 2E,F, blue). In these experiments, only the cotransfection of eYFP-mp5 with mito-RIB(B) resulted in the recruitment of eYFP-mp5 to the mitochondria (Fig. 2E, green); when cotransfected with mitoRIB(A), eYFP-mp5 remained diffusely distributed in the cell (Fig. $2 F$, green).

These experiments confirmed an interaction between Piccolino and the RIBEYE B domain, narrowing down the RIBEYE binding site in Piccolino to its $\mathrm{C}$ terminus.

\section{Piccolino connects RIBEYE molecules via multiple PxDLS-like motifs}

CtBPs interact with PxDLS motif-containing proteins via a PxDLS binding cleft (PxDLS-BC) (Nardini et al., 2003). The Piccolo/Piccolino fragment mp5 possesses a PVDLT sequence that is able to recruit CtBP1 to AZs in primary hippocampal cultures (Ivanova et al., 2015). To test whether the interaction of Piccolino with RIBEYE is mediated via its PxDLS-BC, we first cotransfected NIH 3 T3 cells with full-length RIBEYE containing a mutated PxDLS-BC ( $\mathrm{Ala}^{601} \rightarrow \mathrm{Glu}$ and $\mathrm{Val}^{615} \rightarrow \mathrm{Arg}$; mCherry-RIBEYE ${ }^{\triangle \mathrm{PxDLS}-\mathrm{BC}}$ ) and eYFP-mp5. This mutation was shown to abolish binding of CtBP1 to E1A (Nardini et al., 2003). In our experiments, the amino acid exchange resulted in the loss of the recruitment of eYFP-mp5 to the mutant RIBEYE aggregates (Fig. $3 A$ ). We next verified the involvement of the PVDLT sequence of Piccolino in RIBEYE-binding with an eYFP$\mathrm{mp} 5$ construct in which we mutated the PVDLT motif. The experiment was performed according to a similar experiment that interfered with binding of Ikaros to CtBPs (DL $\rightarrow$ AS) (Koipally and Georgopoulos, 2000). To our surprise, we still detected strong recruitment of eYFP-mp5 $5^{\mathrm{DL} \rightarrow \mathrm{AS}}$ to WT RIBEYE aggregates (data not shown). Even complete mutation of the PVDLT sequence PVDLT $\rightarrow$ RGASI in Piccolino did not abolish recruitment of eYFP-mp5 to the RIBEYE aggregates (Fig. 3B). Subsequent careful analysis of the mp5 amino acid sequence revealed four additional PxDLS-like motifs in mp5, which might contribute to the interaction with the RIBEYE B domain (Fig. 3C).

To test the ability of the RIBEYE B domain to interact with each PxDLS-like motif, we generated subclones of mp5, each containing only one of the PxDLS-like motifs (mp51-mp55; Fig. $3 C$ ), and performed a fusion protein pulldown assay with GSTtagged RIBEYE B domain [GST-RIB(B)] as bait protein. As documented in Figure 3D, GST-RIB(B) was indeed able to strongly bind each of the C-terminal PxDLS-like motifs, whereas two other PxDLS-like motifs localized in the $\mathrm{N}$ terminus (mp11, EADLS) and in the center of Piccolino (mp31, VDDLS) interacted with GST-RIB(B) only very weakly (data not shown) or undetectably (Fig. 3D, lanes 2 and 3).

The presence of multiple interaction motifs in the $\mathrm{C}$ terminus of Piccolino suggests that Piccolino might facilitate linkage of more than one RIBEYE molecule. It is known that CtBPs form homodimers and/or heterodimers, and heterologous expression 
of the RIBEYE B domain alone results in a diffuse fluorescence signal throughout the cell (Schmitz et al., 2000; Magupalli et al., 2008). When we cotransfected mCherry$\mathrm{RIB}(\mathrm{B})$ with one each of the mp5 subclones carrying only a single PxDLS-like motif in NIH 3T3 cells (e.g., eYFP-mp51), we also observed a diffuse fluorescent signal (Fig. 4A). However, when we cotransfected mCherry-RIB(B) together with Piccolino fragments containing two functional PxDLS-like motifs (e.g., eYFPmp56), larger spherical aggregates containing both the RIBEYE B domain and the Piccolino fragment became discernable (Fig. 4B, arrowheads). The cotransfection of mCherry-RIB(B) together with the full complement of PxDLS-like motifs (i.e., eYFP-mp5) resulted in strongest, often perfect, coaggregation of both constructs (Fig. 4C).

Next, we cotransfected untagged RIBEYE together with full-length Piccolino, which, to our surprise, resulted no longer in exclusively spherical but also elongated aggregates (Fig. 4D). The extensions of the elongated aggregates ranged between 1 $\mu \mathrm{m}$ and a few micrometers (not statistically analyzed). This observation further strengthened our hypothesis that Piccolino has a scaffolding function in shaping the SR.

To better understand how Piccolino may physically interact with multiple RIBEYE molecules, we generated a schematic model of interactions based on the suggested arrangement of RIBEYE molecules at the rod photoreceptor SR and the crystal structure of CtBPs (Nardini et al., 2003; Magupalli et al., 2008) (Fig. 5). Previous studies provided evidence that rod photoreceptor SRs are built by two rows of RIBEYE molecules, with the RIBEYE A domains facing the SR matrix and the RIBEYE B domains pointing toward the cytoplasmic face of the ribbon (Magupalli et al., 2008) (Fig. 5A). As CtBPs naturally form dimers, we propose that the smallest structural unit of RIBEYE is a homodimer, which exhibits one PxDLS binding site per RIBEYE B domain subunit (Fig. $5 B$ ). The modeling of higher-

order oligomers using the CtBP2/RIBEYE B domain dimer structure resulted in two regular arrangements, which were characterized by either a loose or a tight packing (Fig. $5 B$ ). The tight packing arrangement was feasible without steric clashes and resulted in a larger interface of the building blocks. Furthermore, the interaction energy in the tight packing was more favorable compared with the loose packing and was thus the favored mode of interaction for all further analyses. In the tight arrangement, all PxDLS binding sites were located on one side of the oligomer (Fig. $5 B$ ), whereas the $\mathrm{N}$ termini of the RIBEYE B domain, which are connected to the A domain, were located on the other side
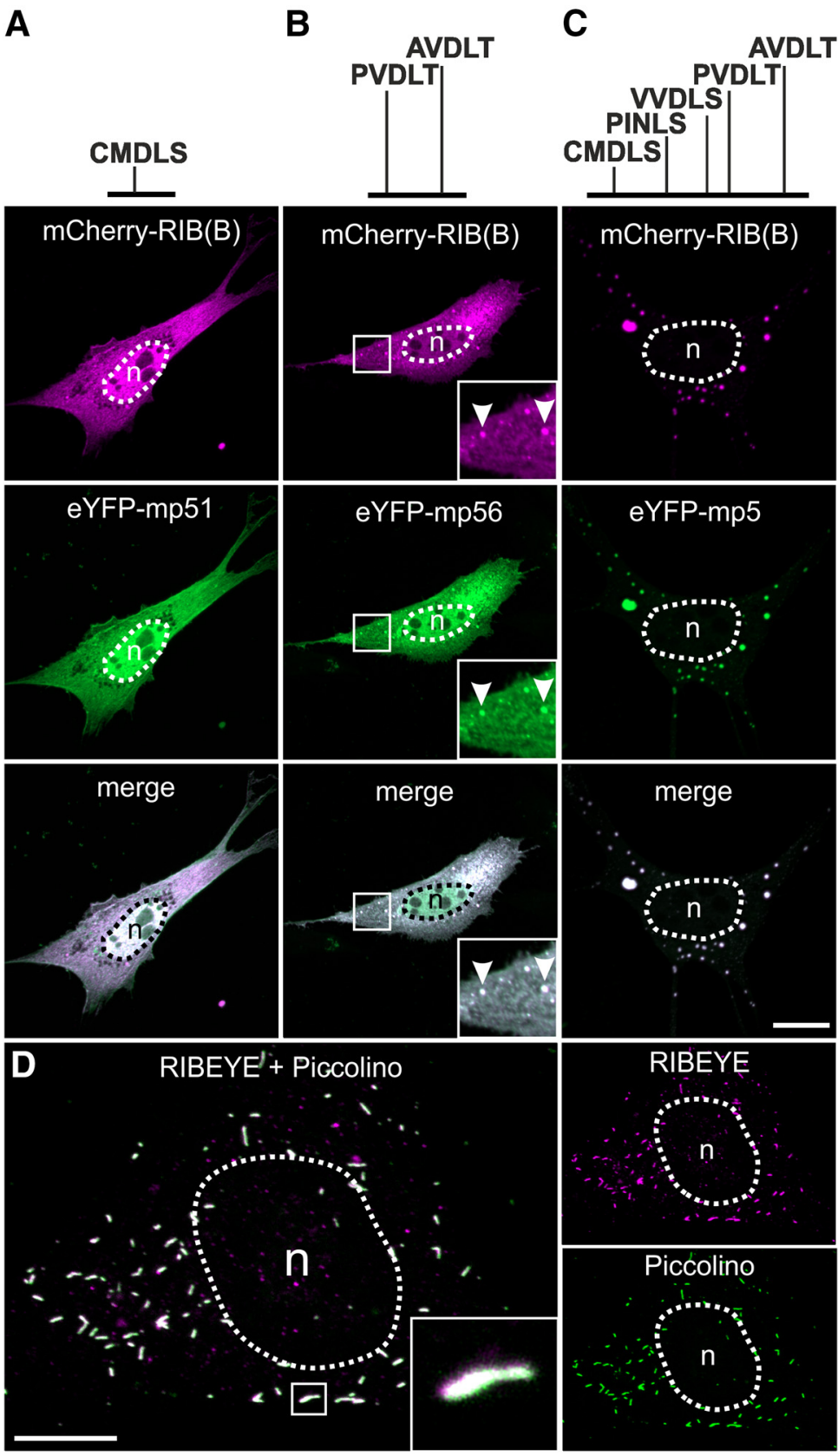

Figure 4. Piccolino $\boldsymbol{C}$ terminus is able to connect RIBEYE B domains. $\boldsymbol{A}-\boldsymbol{C}$, Cotransfected NIH $3 \mathrm{~T} 3$ cells with $\mathrm{mCherry}-\mathrm{RIB}(\mathrm{B})$ $\mathrm{RIB}(\mathrm{B})$ and eYFP-mp56; $n=3$ individual experiments. $\boldsymbol{D}$, NIH $3 \mathrm{~T} 3$ cells expressing full-length Piccolino and RIBEYE. As both proteins were expressed without fluorescent tags, Piccolino was stained with the Pclo44a antibody and RIBEYE with a RIBEYEspecific antibody against its A domain; $n=6$ individual experiments. mp, Mouse Piccolino; n, nucleus. Scale bar, $10 \mu \mathrm{m}$.
(Fig. 5C). In the next step, molecular modeling was used to investigate the potential binding mode of Piccolino in more detail. We generated two different models, both of which allowed Piccolino to bind adjacent RIBEYE B domain dimers, and thereby enforced the formation of higher ordered RIBEYE oligomers (Fig. 5D). In model 1, one single Piccolino molecule occupied all adjacent binding sites, which exhibited distances of 27 and $43 \AA$, respectively. Because the adjacent sites were oriented in an antiparallel fashion, this mode of interaction would require a curled topology of the Piccolino peptide chain. An alternative binding mode (model 2 ) required two 
A

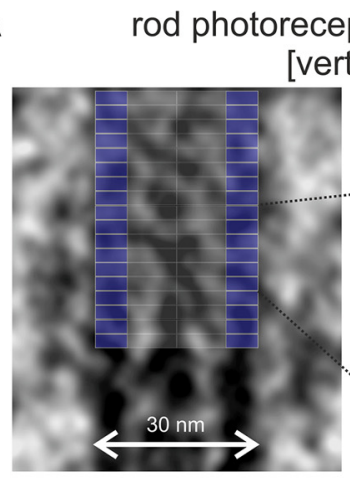

B

hypothetical RIBEYE scaffolding

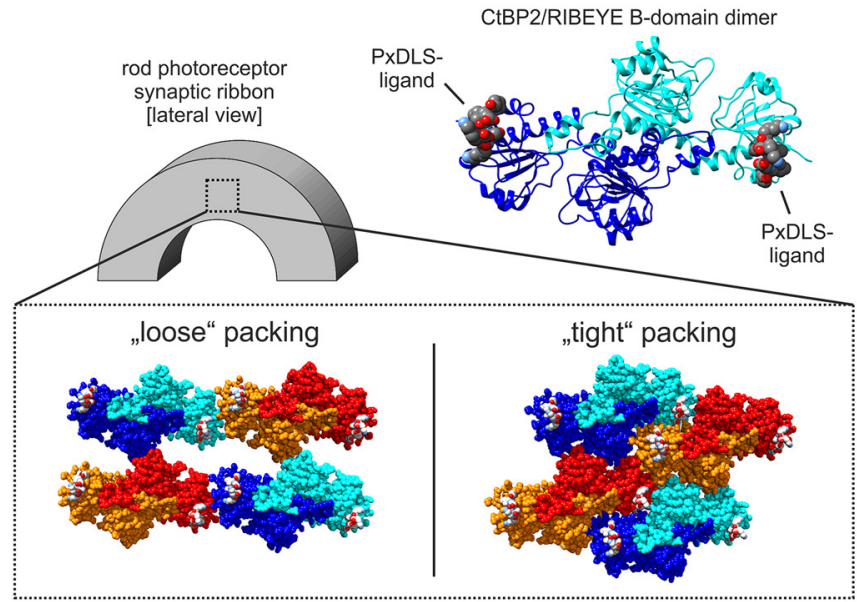

C
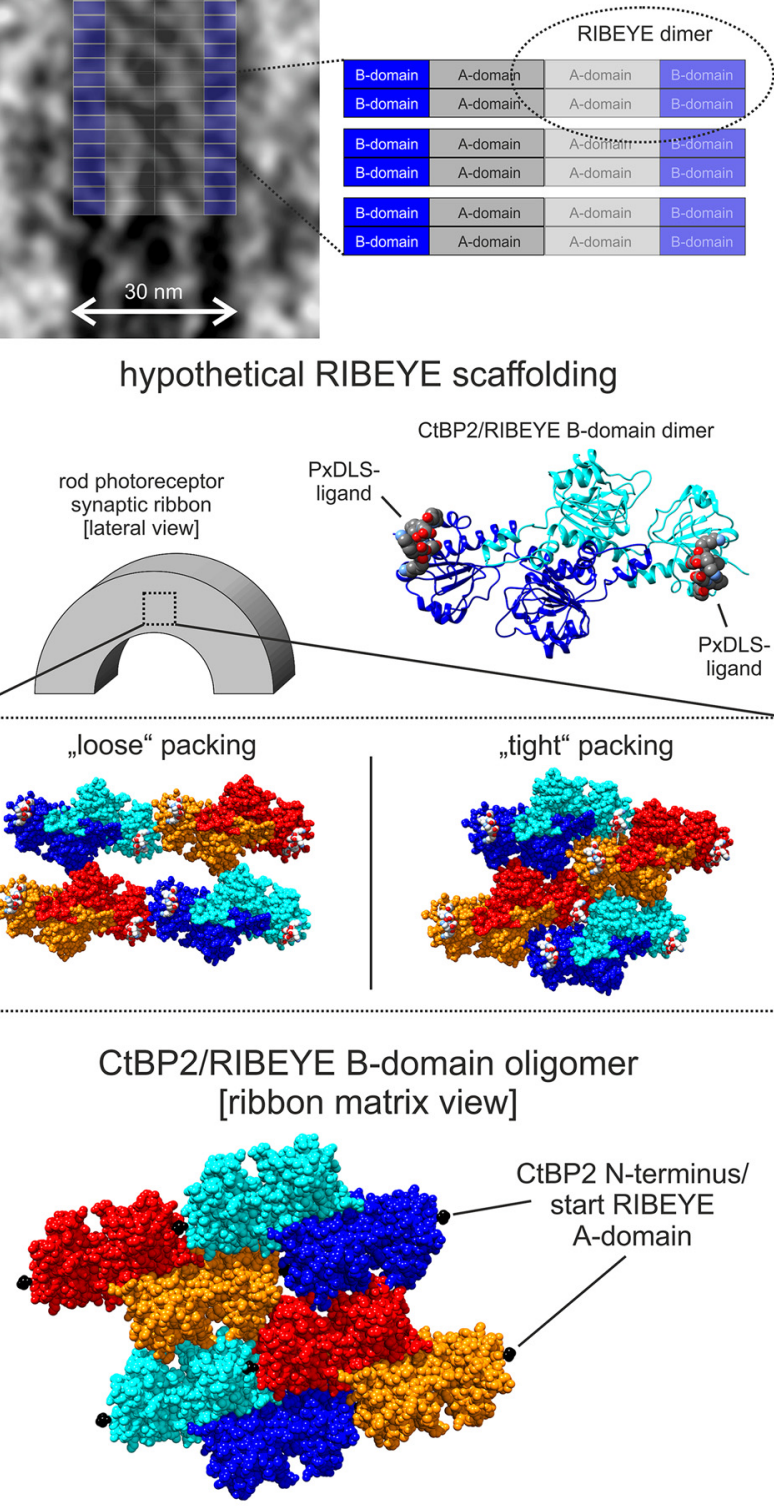

D

CtBP2/RIBEYE B-domain oligomerization [cytoplasmic view]

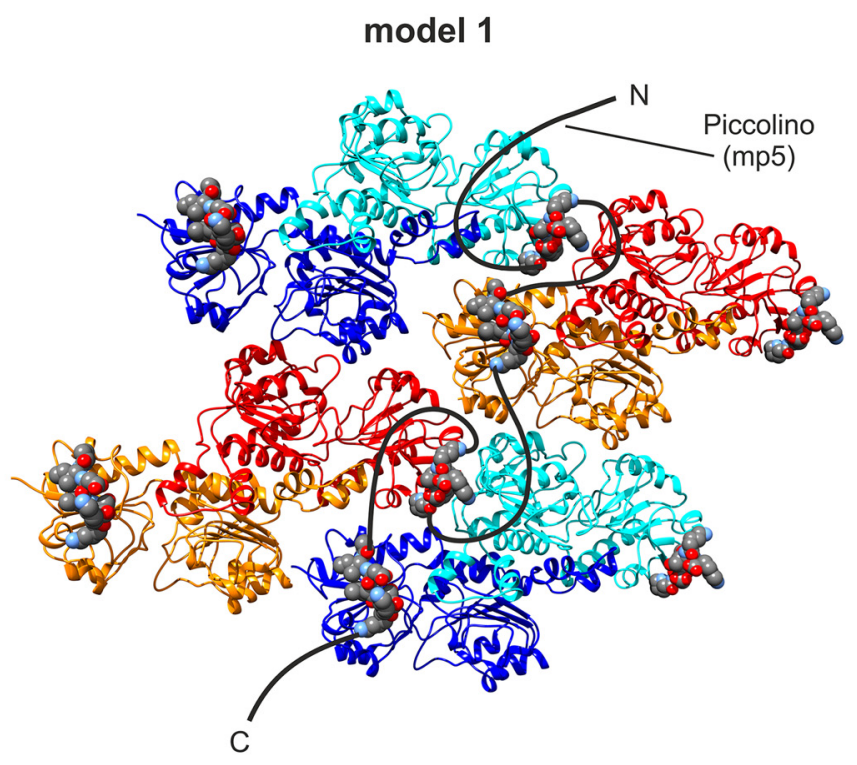

model 2

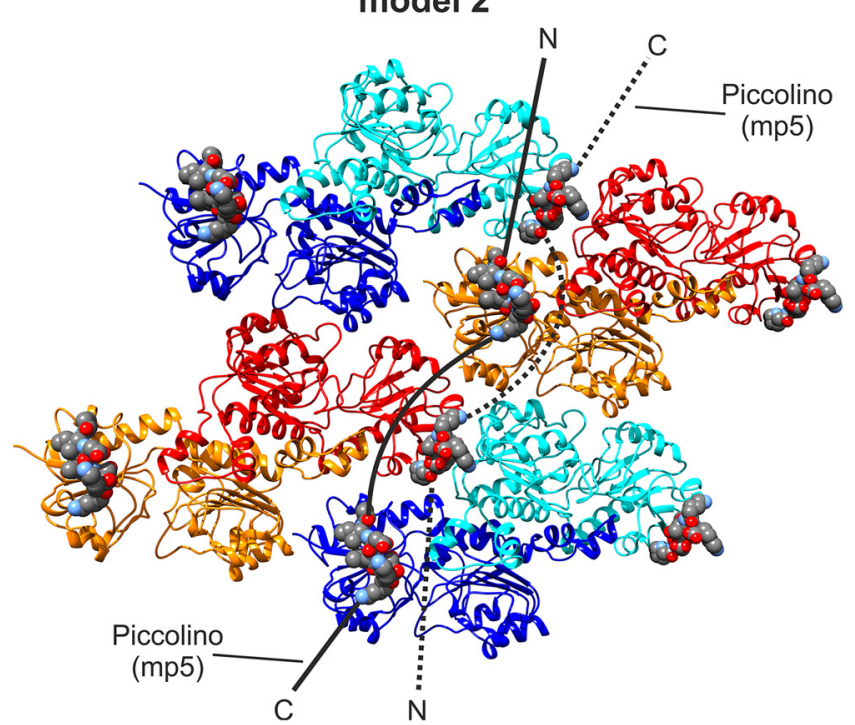

Figure 5. Hypothetical structural model of the Piccolino-RIBEYE interaction at rod photoreceptor SRs. A, High-magnification electron micrograph showing a vertical section of a rod photoreceptor SR, and the proposed orientation of RIBEYE within the SR. In this model, RIBEYE A domains face the center of the SR, and the B domains are exposed to the cytoplasm. $\boldsymbol{B}$, Hypothetical RIBEYE scaffolding. Top right, Blue/cyan represents the crystal structure of the RIBEYE B domain dimers. The bound PxDLS ligand is highlighted in space-filled presentation (coloring according to the atom types). Top left, A rod photoreceptor SR. Bottom, Two possible arrangements of higher-order RIBEYE B domain oligomers (loose vs tight packing) are shown as an enlargement. Adjacent RIBEYE B domain dimers that constitute the oligomer are colored in blue/cyan and red/orange, respectively. The view corresponds to the cytoplasmic side, and the PxDLS ligands binding to this side are colored according to the atom types. C, View from the ribbon matrix side on the RIBEYE B domain oligomer in the tight packing arrangement. The $N$ termini of the B domain, which are connected to the $A$ domain, are located on this side and are marked as black balls. D, Putative binding modes of Piccolino to the RIBEYE B domain oligomer (color coding as in B). In model 1, one single Piccolino molecule (solid black line) occupies all adjacent binding sites by its PxDLS motifs (space-filled presentation). An alternative binding mode (model 2) will require two Piccolino molecules (solid and dotted black line), which are oriented in an antiparallel fashion. Each of them connects those sites, which are oriented in a parallel fashion.

Piccolino molecules, each of them connecting those sites, which were oriented in a parallel fashion. This type of connectivity was in better agreement with a linear Piccolino topology; however, the distance of $\sim 55 \AA$ between the respective binding sites was slightly larger compared with model 1 . We checked whether one of the models could be excluded based on the spacing of the PxDLS-like motifs in Piccolino. Piccolino contains at least five functional PxDLS-like motifs, with a minimal spacer length of 28 residues, which is sufficient to span dis- tances $>55 \AA$. Thus, neither of the two models could be excluded based on the spacer length, and it appeared feasible that both modes of interaction exist at the same time. From the perspective of the SR, this arrangement would place RIBEYE at the core of the SR with Piccolino tethered in a transverse manner that would leave the $\mathrm{N}$-terminal zinc finger domains projecting from the surface. Moreover, it is predicted that the C-terminal PxDLS-like motifs would function to support the core oligomeric structure of RIBEYE. 

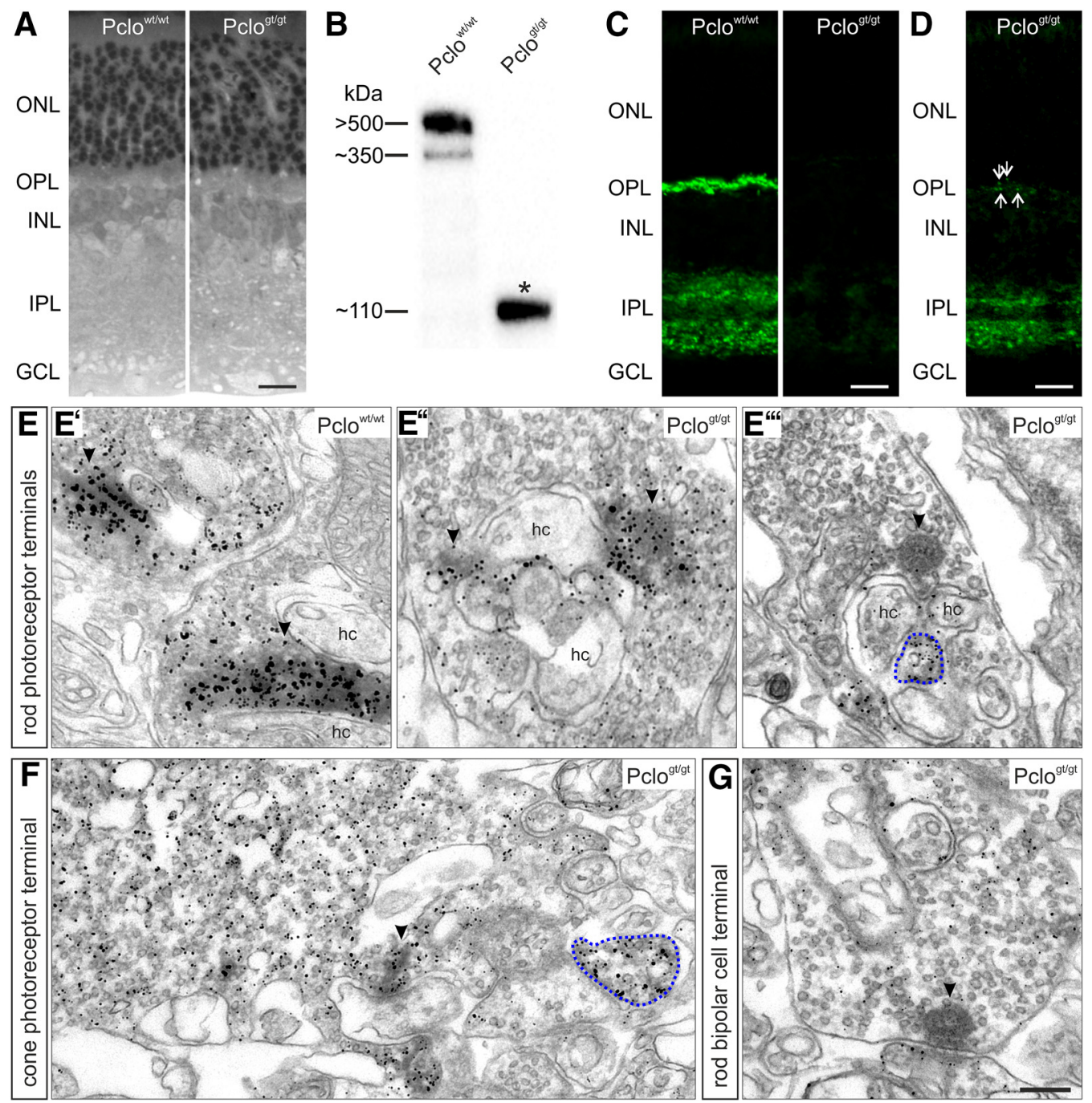

Figure 6. Piccolo/Piccolino are almost completely absent from the Pclo ${ }^{\mathrm{gt} / \mathrm{gt}}$ rat retina. $A$, Toluidine blue staining of vertical Epon-embedded semithin sections of Pclo ${ }^{\mathrm{wt} / \mathrm{wt}}$ and Pclo ${ }^{\mathrm{gt} / \mathrm{gt}}$ rat retina; $n=3$ individual experiments. $\boldsymbol{B}$, Western blot analysis of Pclo ${ }^{\mathrm{wt} / \mathrm{wt}}$ and Pclo ${ }^{\mathrm{gt} / \mathrm{gt}}$ retina lysates stained with the antibody Pclo4 detecting full-length Piccolo $(>500 \mathrm{kDa})$ and Piccolino $(\sim 350 \mathrm{kDa})$ in the Pclo ${ }^{\text {wt/wt }}$ sample. In the Pclo gt/gt sample, only a $\sim 110 \mathrm{kDa}$ fragment is detectable, probably representing the first 3 Pclo exons $(*) ; n=4$ individual experiments. $C$, Vertical cryosections of $\mathrm{Pcl}{ }^{\mathrm{wt} / \mathrm{wt}}$ and $\mathrm{Pcl} 0^{\mathrm{gt} / \mathrm{gt}}$ rat retina labeled with the Pclo4 antibody. Pictures were taken with the same exposure time. $\boldsymbol{D}$, Vertical cryosection of Pclo ${ }^{\mathrm{gt} / \mathrm{gt}}$ rat retina labeled with the Pclo4 antibody. Picture was taken with the optimal exposure time. Arrows indicate weak labeling in the $\mathrm{OPL} ; n=3$ individual experiments. $E-G$, Immunoelectron micrographs of ribbon synapses from Pclo ${ }^{\text {wt/wt }}$ $\left(\boldsymbol{E}^{\prime}\right)$ and $\mathrm{Pcl} 0^{\mathrm{gt} / \mathrm{gt}}\left(\boldsymbol{E}^{\prime \prime}-\boldsymbol{G}\right)$ rat retina labeled with the Pclo4 antibody. Dotted blue line indicates antibody-stained postsynaptic invaginations. GCL, Ganglion cell layer; hc, horizontal cell; INL, inner nuclear layer; $0 \mathrm{NL}$, outer nuclear layer. Scale bars: $\boldsymbol{A}, \boldsymbol{C}, \boldsymbol{D}, 20 \mu \mathrm{m}$; (in $\boldsymbol{G}) \boldsymbol{E}-\mathbf{G}, 0.2 \mu \mathrm{m}$.

\section{Piccolino deficiency leads to disintegration of plate-shaped SRs}

Our modeling predicts that Piccolino might play a role in organizing RIBEYE and other SR-associated proteins, critical for the creation of the plate-shape form of SRs. To test this hypothesis, we examined whether Piccolino loss of function altered the integrity of SRs. This was accomplished by analyzing the retina of a recently generated Piccolo gene trap rat model (Pclo ${ }^{\text {gt/gt; }}$ G.A. Medrano et al., unpublished observations). Retinal anatomy was normal in homozygous Pclo ${ }^{\mathrm{gt} / \mathrm{gt}}$ rats (Fig. 6A), and the number of rows of photoreceptor nuclei was comparable between WT $\left(\mathrm{Pclo}^{\mathrm{wt} / \mathrm{wt}}\right)(13.8 \pm 0.3 ; n=6$ retinal slices $/ 3$ animals $)$ and Pclo ${ }^{\text {gt/gt }}$ retinae $(13.5 \pm 0.3 ; n=6$ retinal slices $/ 3$ animals, $T=$ $1.18 ; \mathrm{df}=4 ; p=0.304$, unpaired $t$ test), indicating that no photoreceptor cell death occurred. To test whether the full-length Piccolo and the ribbon synapse-specific, C-terminally truncated Piccolino (Regus-Leidig et al., 2013) were absent from the $\mathrm{Pclo}^{\mathrm{gt} / \mathrm{gt}}$ rat retina, we performed a Western blot analysis of syn- aptosomal fractions from $\mathrm{Pclo}^{\mathrm{wt} / \mathrm{wt}}$ and $\mathrm{Pclo}{ }^{\mathrm{gt} / \mathrm{gt}}$ retinae with the antibody Pclo4 that recognizes the $\mathrm{N}$ terminus of Piccolo/Piccolino (Fig. 6B). This experiment proved the absence of both Piccolo and Piccolino from the Pclo ${ }^{\mathrm{gt} / \mathrm{gt}}$ retina, but revealed the presence of a shorter $\sim 110 \mathrm{kDa}$ band in the Pclo ${ }^{\text {gt/gt }}$ samples, which most likely represents a residual Piccolo fragment that emerges upon premature translation stop inserted by the genetrap strategy (Fig. 6B, asterisk). To verify the absence of Piccolo/ Piccolino from the two synaptic layers of the retina, the outer plexiform layer (OPL) and inner (IPL) plexiform layer, we stained vertical cryostat sections of $\mathrm{Pclo}^{\mathrm{wt} / \mathrm{wt}}$ and $\mathrm{Pclo}{ }^{\mathrm{gt} / \mathrm{gt}}$ retinae with the Pclo4 antibody. Neither Piccolo (IPL) nor Piccolino (OPL/IPL) was detectable in the Pclo ${ }^{\text {gt/gt }}$ retina (Fig. $6 C$, pictures taken with the same exposure time). However, when we overexposed the images, weak signals became discernible in the OPL (arrows) and IPL of the Pclo ${ }^{\text {gt/gt }}$ retina (Fig. 6D). Immunoelectron microscopy using the Pclo4 antibody revealed that, in the $\mathrm{Pclo}^{\mathrm{gt} / \mathrm{gt}} \mathrm{OPL}$, the signals originated from few, weakly labeled rod 


\section{outer plexiform layer; RIBEYE}
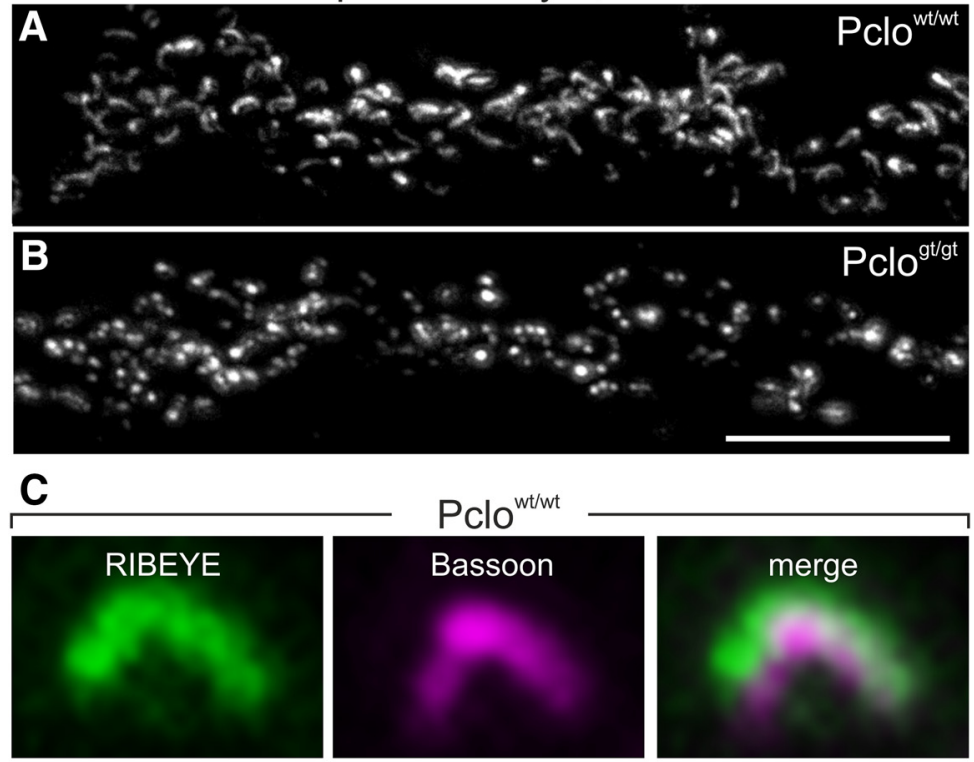

D
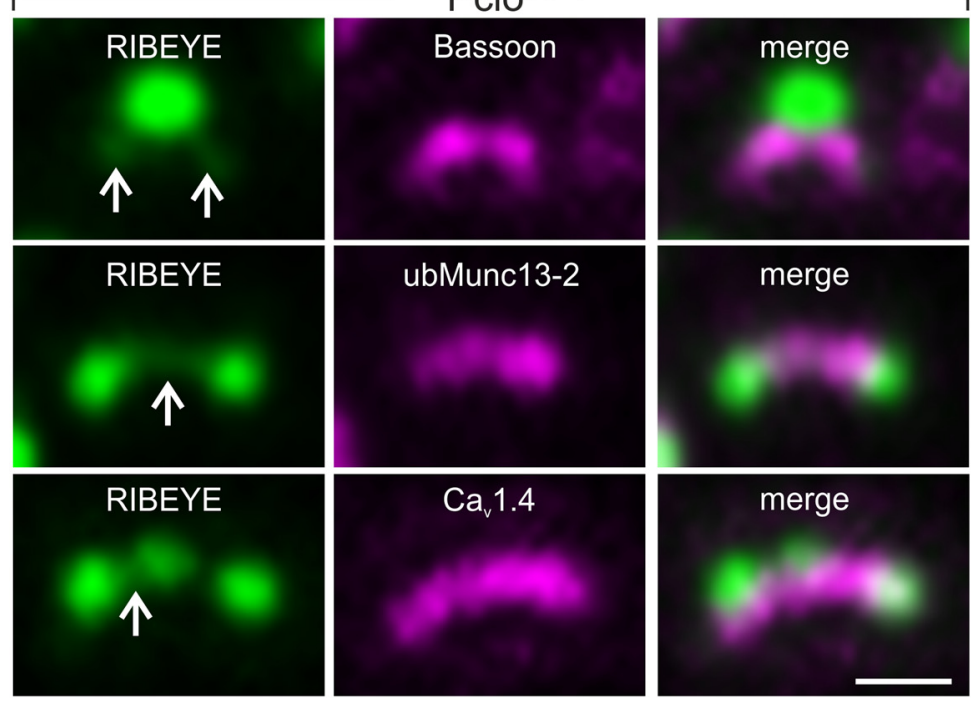

Figure 7. Immunocytochemical analysis of ribbon synapses in the $P c l 0{ }^{g t / g t}$ rat retina. $\boldsymbol{A}, \boldsymbol{B}$, Vertical cryosections of $\mathrm{Pcl}{ }^{\mathrm{wt} / \mathrm{wt}}(\boldsymbol{A})$ and $\mathrm{Pcl}{ }^{\mathrm{gt} / \mathrm{gt}}(\boldsymbol{B})$ OPL stained with an antibody against RIBEYE; $n=3$ individual experiments. $\boldsymbol{C}, \boldsymbol{D}$, Rod photoreceptors of Pclo ${ }^{\mathrm{wt} / \mathrm{wt}}$ $(\boldsymbol{C})$ and $\mathrm{Pcl}{ }^{\mathrm{gt} / \mathrm{gt}}(\boldsymbol{D})$ rat retina double-labeled with antibodies against RIBEYE (green) and Bassoon, ubMunc $13-2$, and Cay 1.4 (all magenta), respectively. Arrows indicate the very weak remaining horseshoe-shaped fluorescence at the basis of $S R$ s in the absence of Piccolino; $n=3$ individual experiments. Scale bars: (in $\boldsymbol{B}) \boldsymbol{A}, \boldsymbol{B}, 10 \mu \mathrm{m}$; (in $\boldsymbol{D}) \boldsymbol{C}, \boldsymbol{D}, 1 \mu \mathrm{m}$.

photoreceptor SRs; most of the rod photoreceptor SRs in the Pclo ${ }^{\text {gt/gt }}$ OPL were unstained (Fig. 6E", $E^{\prime \prime \prime}$; compare staining intensity to the Pclo ${ }^{\mathrm{wt} / \mathrm{wt}}$ in Fig. $6 E^{\prime}$ ). In some cone photoreceptor terminals in the OPL and bipolar cell terminals in the IPL, we found weak, evenly distributed Pclo4 signals without any concentration at the AZs/SRs (Fig. 6F,G). We also detected Piccolo/ Piccolino immunoreactivity in several postsynaptic invaginating elements, presumably bipolar cell dendrites, in the OPL (Fig. $6 E^{\prime \prime \prime}, F$, blue dotted lines). In this analysis, SRs in the Pclo ${ }^{\mathrm{gt} / \mathrm{gt}}$ retina often appeared spherically instead of plate-shaped (Fig. $\left.6 E^{\prime \prime}, E^{\prime \prime \prime}, G\right)$, which was comparable with our reported Piccolino knockdown SR phenotype in the mouse retina (Regus-Leidig et al., 2014).

To address the structural SR phenotype in $\mathrm{Pclo}^{\mathrm{gt} / \mathrm{gt}}$ retina in more detail, we first compared rod photoreceptor AZs in vertical cryostat sections of Pclo ${ }^{\mathrm{wt} / \mathrm{wt}}$ and $\mathrm{Pclo}^{\mathrm{gt} / \mathrm{gt}}$ retinae with immunocytochemistry and high-resolution light microscopy with an antibody against RIBEYE (Fig. 7). While in the Pclo ${ }^{\text {wt/wt }}$ OPL, rod photoreceptor SRs displayed the typical horseshoe shape (Fig. $7 A, C$ ), in the Pclo ${ }^{\text {gt/gt }}$ OPL, the RIBEYE antibody often produced staining of spherical structures (Fig. $7 B, D$ ). Immunocytochemical double stainings further revealed that, while the general appearance of the arciform density showed only mild alterations in the Pclo ${ }^{\mathrm{gt} / \mathrm{gt}}$ OPL $(\alpha$ Bassoon, $\alpha$-ubMunc13-2, $\alpha-\mathrm{Ca}_{\mathrm{v}} 1.4$; magenta; Fig. $7 C, D$ ), the fragmented RIBEYE staining appeared as one or more spherical aggregates per AZ (Fig. 7D). As these spherical RIBEYE aggregates sat on top of the $\mathrm{AZ}$ and were connected by a thin horseshoe-shaped layer of RIBEYE fluorescence (Fig. $7 D$, arrowheads), we assume that the basal row of RIBEYE molecules was still attached to the arciform density, whereas the remaining RIBEYE molecules failed to be properly arranged. Quantification of the lateral extension of the rod photoreceptor SR ( $\alpha$ RIBEYE) and AZ ( $\alpha$-Bassoon) in wholemount preparations of $\mathrm{Pclo}{ }^{\mathrm{wt} / \mathrm{wt}}$ and $\mathrm{Pclo}^{\mathrm{gt} / \mathrm{gt}}$ retinae revealed a significant length reduction of both compartments by $\sim 20 \%$ in the absence of Piccolino (SR: Pclo $^{\text {wt/wt }}: 1808 \pm 102 \mathrm{~nm} ;$ Pclo $^{\mathrm{gt} / \mathrm{gt}}$ : $1395 \pm 58 \mathrm{~nm} ; T=4,966 ; \mathrm{df}=4 ; p=$ 0,008; $n=3$ animals; AZ: Pclo ${ }^{\mathrm{wt} / \mathrm{wt}}$ : $1600 \pm 37 \mathrm{~nm} ;$ Pclo $^{\text {gt/gt }}: 1315 \pm 57 \mathrm{~nm}$; $\mathrm{T}=5,903 ; \mathrm{df}=4 ; p=0.008, n=3$ animals; unpaired $t$ test). Of note, some $\mathrm{Pclo}^{\mathrm{gt} / \mathrm{gt}}$ retinae displayed RIBEYE stainings in rod photoreceptors that were similar to Pclowt/wt, indicating a variable effect of the Piccolo deficiency on SR structure (data not shown).

Next, we 3D reconstructed ribbon synaptic complexes (pre-SR and postsynaptic invaginating elements) of rod photoreceptors from serial ultrathin sections of $\mathrm{Pclo}^{\mathrm{wt} / \mathrm{wt}}$ and $\mathrm{Pclo}^{\mathrm{gt} / \mathrm{gt}}$ retinae (Fig. $\left.8 A, A^{\prime}, B, B^{\prime}\right)$. 3D reconstructed Pclo ${ }^{\mathrm{wt} / \mathrm{wt}}$ rod photoreceptor SRs showed the typical horseshoe shape with a height of $235 \pm 23 \mathrm{~nm}$ and a length of $1715 \pm 299 \mathrm{~nm}(n=6$ SRs from 3 animals; Fig. $\left.8 A, A^{\prime}\right)$. Residual horseshoe-shaped SR material in $\mathrm{Pclo}^{\mathrm{gt} / \mathrm{gt}} \mathrm{rod}$ photoreceptors was reduced in height and length (height, $86 \pm 23$ nm; length, $1263 \pm 293 \mathrm{~nm} ; n=6$ SRs from 3 animals) and frequently spherical aggregates appeared at the AZ (Fig. $8 B, B^{\prime}$ ). The number of large spherical aggregates varied from one to three per AZ.

To analyze whether the observed structural alterations of SRs in Piccolino-deficient rod photoreceptors are valid for all types of retinal ribbon synapses, we extended our ultrastructural analysis to cone photoreceptors (Fig. $8 C, C^{\prime}, D, D^{\prime}$ ), and rod bipolar cells (Fig. $8 E, F)$. Cone photoreceptor SRs, like rod photoreceptor 


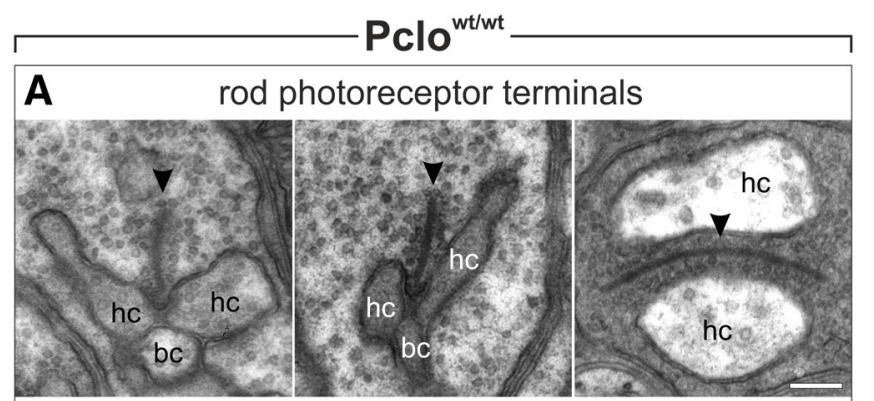

$A^{\prime}$
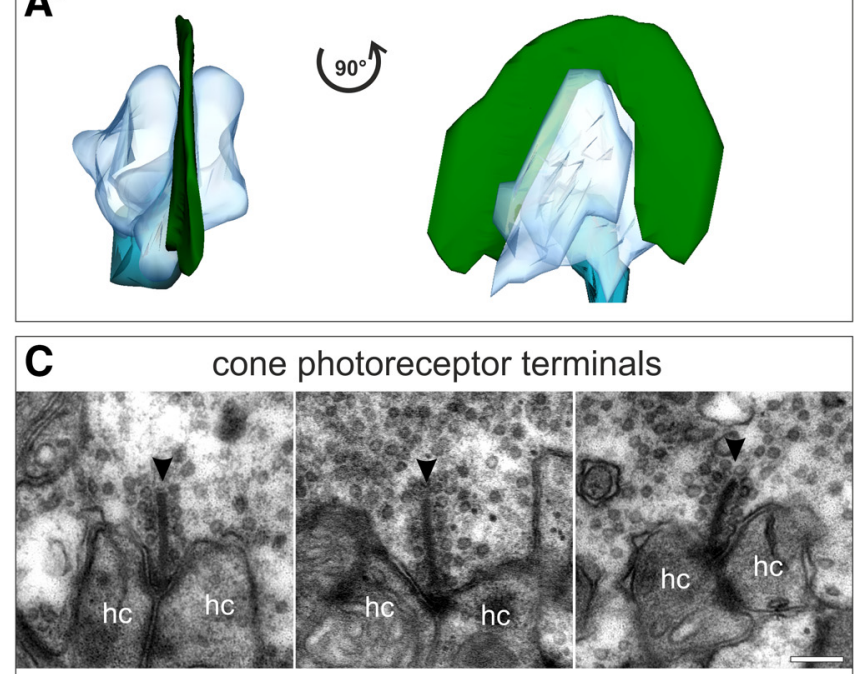

C'
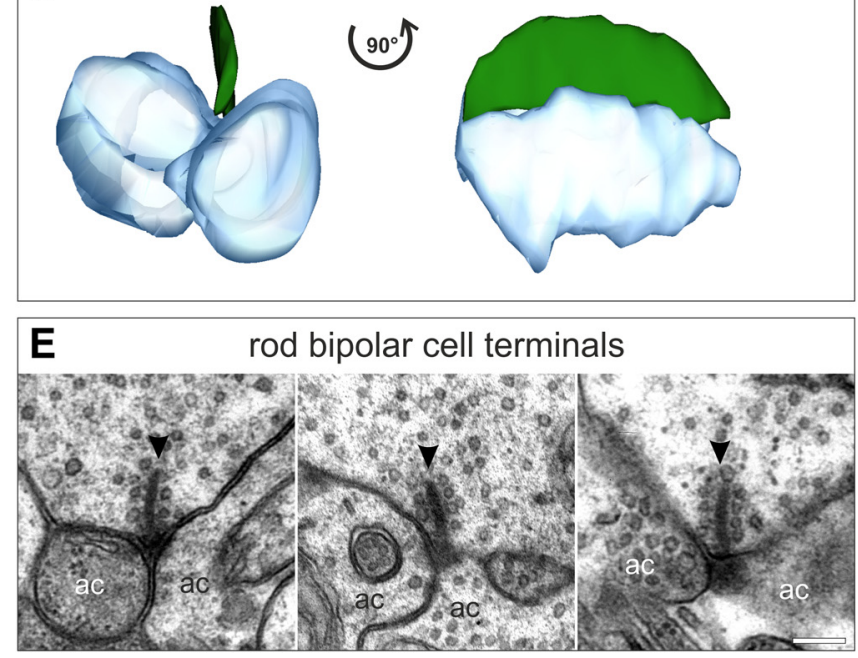

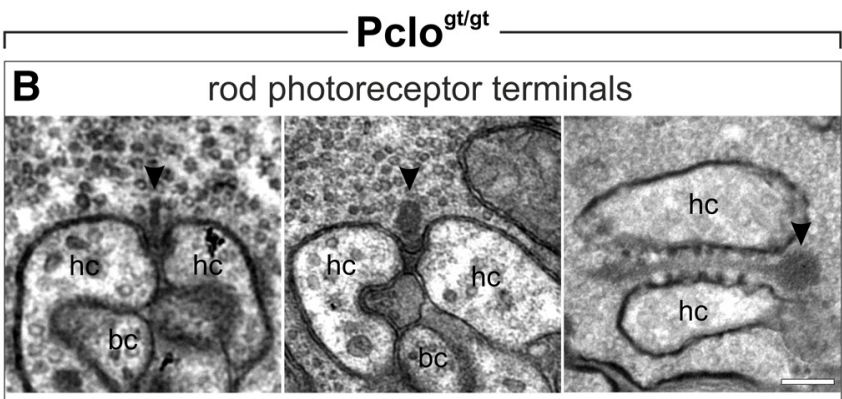

B'
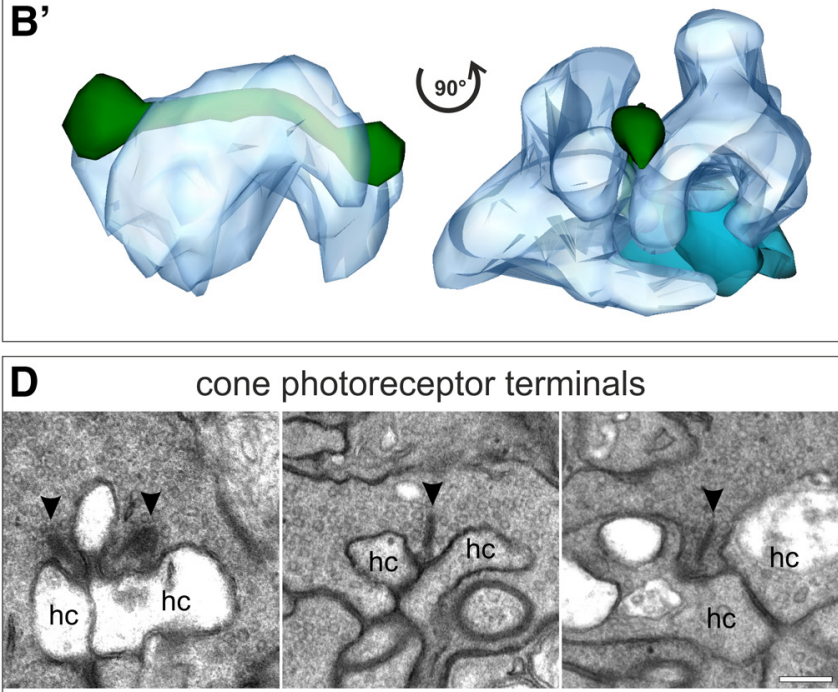

D'
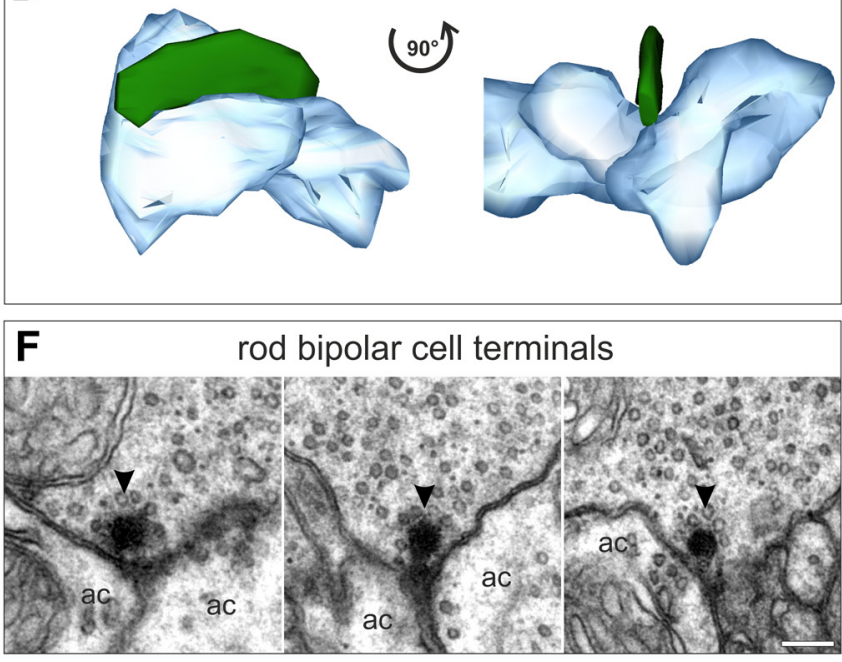

Figure 8. Ultrastructural analysis of ribbon synapses in the $\mathrm{Pcl}{ }^{\mathrm{gt} / \mathrm{gt}}$ rat retina. $\boldsymbol{A}, \boldsymbol{A}^{\prime}, \boldsymbol{B}, \boldsymbol{B}^{\prime}$, Representative electron micrographs of three rod photoreceptor synaptic terminals and a corresponding $3 D$ reconstruction of one SR in the Pclo ${ }^{\text {wt } / \text { wt }}\left(\boldsymbol{A}, \boldsymbol{A}^{\prime}\right)$ and $\mathrm{Pcl} 0^{\mathrm{gt} / \mathrm{gt}}$ rat retina $\left(\boldsymbol{B}, \boldsymbol{B}^{\prime}\right) . \boldsymbol{C}, \boldsymbol{C}^{\prime}, \boldsymbol{D}, \boldsymbol{D}^{\prime}$, Representative electron micrographs of three cone photoreceptor synaptic terminals and a corresponding $3 \mathrm{D}$ reconstruction of one $S R$ in the $\mathrm{Pcl}{ }^{\text {wt } / \text { wt }}\left(\boldsymbol{C}, \boldsymbol{C}^{\prime}\right)$ and $\mathrm{Pcl} 0^{\mathrm{gt} / \mathrm{gt}}$ rat retina $\left(\boldsymbol{D}, \boldsymbol{D}^{\prime}\right) . \boldsymbol{E}, \boldsymbol{F}$, Representative electron micrographs of three rod bipolar cell synapses in the $\mathrm{Pcl}{ }^{\text {wt }}$ /wt $(\boldsymbol{E})$ and $\mathrm{Pcl}^{\mathrm{gt} / \mathrm{gt}}$ rat retina $(\boldsymbol{F})$. Because of their small size, bipolar ribbons were not reconstructed. Arrowheads indicate $S R s ; n=3$ individual experiments. ac, Amacrine cell; bc, bipolar cell; $h c$, horizontal cell. Scale bars, $0.2 \mu \mathrm{m}$.

SRs, were reduced in height and length in $\mathrm{Pclo}^{\text {gt/gt }}$ retinae $\left(\mathrm{Pclo}^{\mathrm{wt} / \mathrm{wt}}\right.$ : height, $273 \pm 66 \mathrm{~nm}$; length, $1088 \pm 517 \mathrm{~nm}$; Pclo ${ }^{\mathrm{gt} / \mathrm{gt}}$ : height, $214 \pm 65 \mathrm{~nm}$; length, $606 \pm 170 \mathrm{~nm} ; n=5$ or 6 SRs from 3 animals/genotype; Fig. $\left.8 C, C^{\prime}, D, D^{\prime}\right)$, but to our surprise, we very rarely observed spherical ribbon material. Rod bipolar cell SRs in Pclo ${ }^{\text {wt/wt }}$ retina were predominantly plate-shaped with a mean height of $180 \pm 43 \mathrm{~nm}(n=77$ SRs from 3 animals; Fig. $8 E)$. In contrast, the majority of rod bipolar cell SRs in Pclo ${ }^{\text {gt/gt }}$ retina displayed a spherical or oval architecture in single ultrathin sec- tions with a mean diameter of $124 \pm 20 \mathrm{~nm}(n=75$ SRs from 3 animals; Fig. $8 F$ ). Because of their small size, we did not $3 \mathrm{D}$ reconstruct SRs from rod bipolar cells.

Piccolino deficiency moderately affects photoreceptor ribbon synaptic transmission

We further examined the retinal physiology of Pclo ${ }^{\mathrm{wt} / \mathrm{wt}}$ and Pclo $^{\text {gt/gt }}$ rats with ERG recordings. Although the Pclo ${ }^{\text {gt/gt }}$ rats showed a higher variance of the functional phenotype than 
A scotopic flash ERG [log phot cd.s/m²]

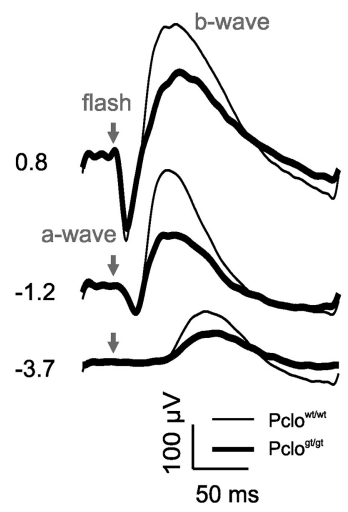

C photopic flash ERG [log phot cd.s $/ \mathrm{m}^{2}$ ]
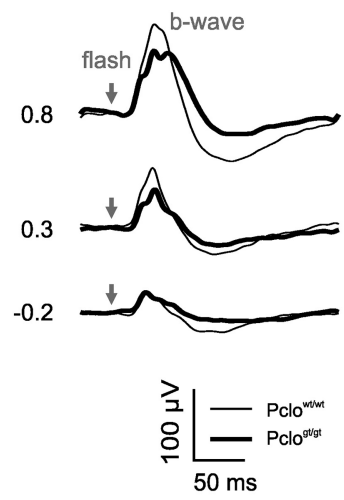

B scotopic response vs. flash intensity profiles

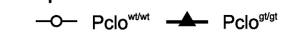
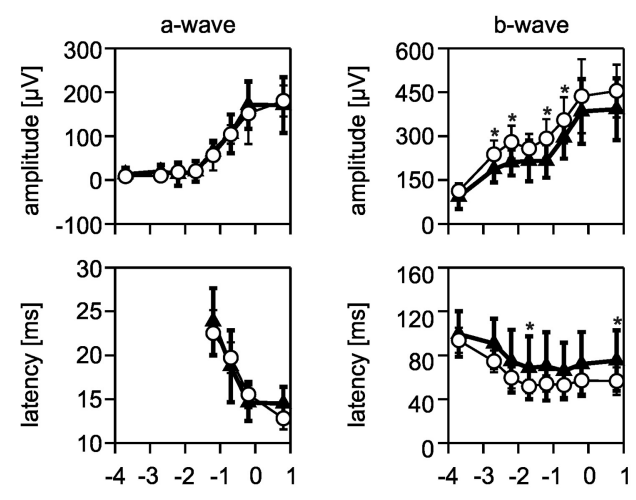

flash intensity [log phot cd.s $/ \mathrm{m}^{2}$ ]
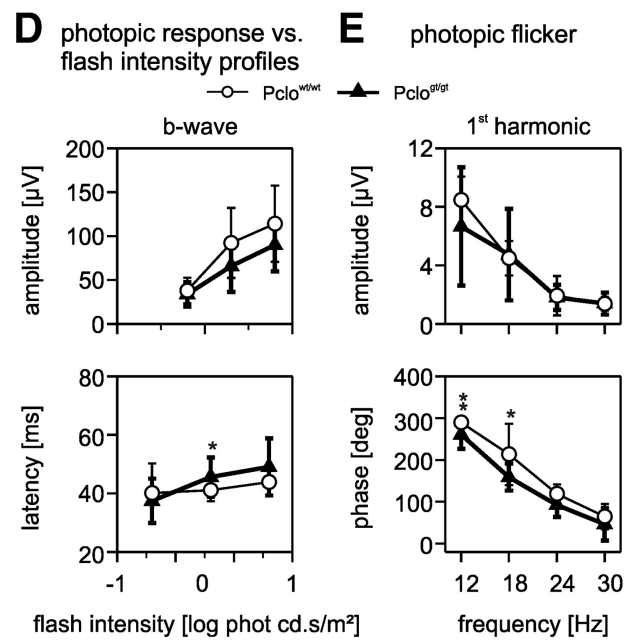

Figure 9. ERG recordings of Pclo ${ }^{\text {wt } / \mathrm{wt}}$ and Pclo ${ }^{\mathrm{gt} / \mathrm{gt}}$ rats. $\boldsymbol{A}$, ERG responses to a $-3.7,-1.2$, and $0.8 \log \mathrm{cd} \cdot \mathrm{s} / \mathrm{m}^{2}$ flash are shown for $\mathrm{Pcl}{ }^{\mathrm{wt} / \mathrm{wt}}$ (thin line, mean) and $\mathrm{Pcl}{ }^{\mathrm{gt} / \mathrm{gt}}$ (thick line, mean) rats. Gray arrow indicates time point of the flash stimulus. $\boldsymbol{B}$, Summary of amplitude and latency of the scotopic ERG components. Open circles represent Pclowt/wt (mean \pm SD). Closed triangles represent $\mathrm{Pcl}{ }^{\mathrm{gt} / \mathrm{gt}}$ (mean \pm SD). C, ERG responses to $-0.2,0.3$, and $0.8 \mathrm{log} \mathrm{cd} \cdot \mathrm{s} / \mathrm{m}^{2}$ photopic flash $\left(25 \mathrm{~cd} / \mathrm{m}^{2}\right.$ white background light). For details of presentation, see description of $\boldsymbol{A}$. $\boldsymbol{D}$, Summary of the main components of the photopic flash ERG (a-wave smaller than $10 \mu V$ and therefore not shown). For details of presentation, see description of $\boldsymbol{B}$. $\boldsymbol{E}$, Amplitude and phase of the first harmonic of the photopic flicker ERG shown as a function of frequency. For details of presentation, see description of $\boldsymbol{B}$. Pclo ${ }^{\text {wt } / \text { wt. }} n=9 ;$ Pclo $^{\text {gt } / g t}: n=13 .{ }^{*} p<0.05 ;{ }^{* *} p<0.005$

Pclo ${ }^{\text {wt/wt }}$ rats, the ERG recordings revealed only moderate alterations in photoreceptor ribbon synaptic transmission in Pclo ${ }^{\mathrm{gt} / \mathrm{gt}}$ compared with Pclo ${ }^{\mathrm{wt} / \mathrm{wt}}$ rats. The scotopic flash ERG showed an increase in amplitude and a decrease in response latency with increasing flash strength for Pclo ${ }^{\mathrm{wt} / \mathrm{wt}}$ and $\mathrm{Pclo}^{\mathrm{gt} / \mathrm{gt}}$. The $\mathrm{Pclo}^{\mathrm{gt} / \mathrm{gt}}$ rats revealed slightly, but not consistently, significant smaller b-waves (Fig. $9 A, B ; p<0.05$, Kruskal-Wallis test). The results from the photopic flash ERG recordings showed an increase in amplitude and latency with increasing flash strength for Pclo wt/wt and Pclo ${ }^{\mathrm{gt} / \mathrm{gt}}$. The photopic ERGs of the Pclo ${ }^{\mathrm{g} / \mathrm{gt}}$ rats did not differ from the Pclo ${ }^{\mathrm{wt} / \mathrm{wt}}$ rats (Fig. $9 C, D ; p<0.05$, Kruskal-Wallis test). Figure $9 E$ presents the quantitative analysis of amplitude and phase of the first harmonic of the photopic flicker ERG. Both amplitude and phase of the fundamental components decreased with increasing stimulus frequency. The Pclo ${ }^{\mathrm{gt} / \mathrm{gt}}$ rats showed just a slight trend for a phase shift compared with the $\mathrm{Pclo}^{\mathrm{wt} / \mathrm{wt}}$ rats (Fig. $9 E ; p<0.05, p<0.005$, Kruskal-Wallis test). Summarizing the ERG analysis, we observed only minor differences in photoreceptor ribbon synaptic transmission between $\mathrm{Pclo}^{\mathrm{wt} / \mathrm{wt}}$ and Pclo ${ }^{\mathrm{gt} / \mathrm{gt}}$ rats.

\section{Discussion}

The architecture of chemical synapses varies greatly, and the common view is that structural differences correlate with the specific functional requirements of a given synapse (Lenzi and von Gersdorff, 2001; Zhai and Bellen, 2004; Matthews and Fuchs, 2010). One of the most complex chemical synapses in vertebrates is the continuously releasing ribbon-type synapse found in sensory neurons (e.g., photoreceptors in the eye and inner hair cells in the cochlea) (Matthews and Fuchs, 2010). Ribbon synapses possess a remarkable 3D extension of the AZ, the SR, which varies in size and shape among different types of neurons. The main component of SRs is RIBEYE, a CtBP2 isoform unique to ribbon synapses, and possibly the most striking evolutionary adaptation to the functional demands of sensory synaptic AZs (Schmitz et al., 2000). Expression of RIBEYE in vitro is sufficient for the formation of unstructured spherical aggregates, as RIBEYE can self-assemble via heterotypic interactions between its $\mathrm{A}-$ and $\mathrm{B}$ domain (Magupalli et al., 2008). However, the sole expression of RIBEYE does not suffice to create the elongated, plateshaped SRs as, for example, displayed by vertebrate photoreceptors or rod bipolar cells of the retina (Magupalli et al., 2008; current study).

In the present study, we pursued the question of whether Piccolino, the ribbon synapse-specific splice variant of the AZ scaffold protein Piccolo, plays a role in shaping the plate-like ribbon structure in photoreceptors and bipolar cells. The results of our experiments suggest the necessity of an interaction between Piccolino and RIBEYE to create and/or maintain a plate-shaped ribbon architecture. Multiple connections of RIBEYE B domains with the C terminus of Piccolino favor homotypic RIBEYE interactions and thereby impose an ordered arrangement onto the RIBEYE aggregates. While the $\mathrm{C}$ terminus of Piccolino was sufficient to connect RIBEYE molecules, we only observed spherical aggregates upon coexpression in NIH 3T3 cells. However, coexpression of RIBEYE together with full-length Piccolino often resulted in elongated Piccolino-RIBEYE aggregates in vitro. We currently can only speculate that the long $\mathrm{N}$ terminus of Piccolino may be able to sterically hinder RIBEYE molecules from adopting an unstructured aggregation.

This scaffolding function of Piccolino seems to apply especially to SRs in rod photoreceptors and rod bipolar cells. In these neurons, Piccolino deficiency alters ribbon architecture, leading to spherical ribbon aggregates at the AZ (Regus-Leidig et al., 2014; the current study). In cone photoreceptors, Piccolino deficiency produces smaller ribbons but rarely spherical ribbon aggregates. So far, we have no explanation why the ribbon phenotype differs between rod and cone photoreceptors in the 
Pclo ${ }^{\text {gt/gt }}$ retina, although we propose that an additional structurally organizing molecule must be present in these cells to facilitate the formation of a flat SR by RIBEYE.

Inner hair cells of the cochlea express also Piccolino and RIBEYE, yet they primarily display spherical-shaped SRs (Moser et al., 2006; Safieddine et al., 2012; Regus-Leidig et al., 2013; Nicolson, 2015; Wichmann and Moser, 2015). Hence, the question arises why our proposed RIBEYE-Piccolino interaction model does not apply to this type of ribbon synapse. One explanation could be differences in the RIBEYE:Piccolino ratios among the different types of ribbon synapses. In semiquantitative Western blots of retinal lysates, we observed a RIBEYE:Piccolino ratio of $\sim 1: 1$ (data not shown). In the case of spherical-shaped inner hair cell ribbons, the number of RIBEYE molecules could exceed the number of Piccolino molecules, thus preventing Piccolino from enforcing a regular, plate-shaped arrangement of the RIBEYE proteins. Unfortunately, this experiment is difficult to perform in the cochlea because of the low abundance of hair cell SRs.

To assess retinal function in the absence of Piccolo/Piccolino in vivo, we performed ERG recordings from $\mathrm{Pclo}^{\mathrm{wt} / \mathrm{wt}}$ and $\mathrm{Pclo}^{\text {gt/gt }}$ rats. Because deletion of the Piccolo homolog Bassoon leads to a strong functional impairment of synaptic transmission from photoreceptors to bipolar cells (Dick et al., 2003), we were surprised that the ERG recordings from $\mathrm{Pclo}^{\mathrm{gt} / \mathrm{gt}}$ rats did not greatly differ from the $\mathrm{Pclo}^{\mathrm{wt} / \mathrm{wt}}$ recordings. The $\mathrm{Pclo}^{\mathrm{gt} / \mathrm{gt}}$ rats showed a moderately, but not significantly, delayed b-wave in the scotopic flash ERGs. Interestingly, the scotopic flash ERGs, which represent rod photoreceptor-driven synaptic transmission, showed a stronger reduction in the b-wave amplitude than the photopic flash ERGs, representing cone photoreceptor synaptic transmission. This fits well with our observation that, in $\mathrm{Pclo}^{\mathrm{gt} / \mathrm{gt}}$ rats, the structure of rod photoreceptor SRs was more affected than the structure of cone photoreceptor SRs. Our data also show a correlation between SR and AZ size and the strength of synaptic transmission. In $\mathrm{Pclo}^{\text {gt/gt }}$ rats, SR and AZ size was reduced by $\sim 20 \%$, which correlates approximately to the measured reduction of $12 \%-26 \%$ in the scotopic b-wave amplitudes. This finding agrees with earlier findings on the disruption of the AZ protein CAST/ERC2, where a reduction of the rod photoreceptor AZ size went along with diminished amplitudes of the b-wave in scotopic ERGs (tom Dieck et al., 2012).

A recent publication showed that overexpression of RIBEYE in zebrafish hair cells resulted in enlarged SRs, increased calcium currents, but disrupted afferent spontaneous activity and timing of stimulus onset (Sheets et al., 2017). Therefore, a tight control of the RIBEYE level and its ratio to other AZ proteins seem to be essential for the kinetics of ribbon synaptic release. In addition to the size (and potentially shape) of SRs, the total amount of Piccolino and Piccolino-associated proteins will probably also have an impact on ribbon synaptic function. Despite the large C-terminal truncation, Piccolino is still a large protein $(\mathrm{mW}$ $\sim 330 \mathrm{kDa}$ ) with multiple protein binding domains (RegusLeidig et al., 2013). According to our model, the $\mathrm{N}$ terminus of Piccolino faces the cytoplasmic site of the SR, where it could interact with other ribbon-associated or cytoplasmic proteins and, for example, regulate certain steps in the SV cycle (Wang et al., 1999; Fenster et al., 2000, 2003; Kim et al., 2003; Waites et al., 2011, 2013; Wagh et al., 2015; Terry-Lorenzo et al., 2016).

In conclusion, we demonstrate an interaction between Piccolino and RIBEYE and provide a structural model for how Piccolino could contribute to defining the shape of SRs in the retina. In support of our model, genetic manipulation of Piccolino in the
Pclo ${ }^{\text {gt/gt }}$ rat altered SR shape, a structural phenotype that cannot be compensated by Bassoon. As Piccolino and Bassoon fulfill complementary and nonredundant functions at ribbon synapses, this might explain why sensory neurons, such as photoreceptors, are more susceptible than conventional chemical synapses to structural and functional impairments in the absence of either Piccolo/Piccolino or Bassoon.

\section{References}

Ackermann F, Waites CL, Garner CC (2015) Presynaptic active zones in invertebrates and vertebrates. EMBO Rep 16:923-938.

Butola T, Wichmann C, Moser T (2017) Piccolo promotes vesicle replenishment at a fast central auditory synapse. Front Synaptic Neurosci 9:14.

Cases-Langhoff C, Voss B, Garner AM, Appeltauer U, Takei K, Kindler S, Veh RW, De Camilli P, Gundelfinger ED, Garner CC (1996) Piccolo, a novel $420 \mathrm{kDa}$ protein associated with the presynaptic cytomatrix. Eur J Cell Biol 69:214-223.

Cooper B, Hemmerlein M, Ammermüller J, Imig C, Reim K, Lipstein N, Kalla S, Kawabe H, Brose N, Brandstätter JH, Varoqueaux F (2012) Munc13independent vesicle priming at mouse photoreceptor ribbon synapses. J Neurosci 32:8040-8052.

Dick O, Hack I, Altrock WD, Garner CC, Gundelfinger ED, Brandstätter JH (2001) Localization of the presynaptic cytomatrix protein piccolo at ribbon and conventional synapses in the rat retina: comparison with Bassoon. J Comp Neurol 439:224-234.

Dick O, tom Dieck S, Altrock WD, Ammermüller J, Weiler R, Garner CC, Gundelfinger ED, Brandstätter JH (2003) The presynaptic AZ protein Bassoon is essential for photoreceptor ribbon synapse formation in the retina. Neuron 37:775-786.

Fenster SD, Chung WJ, Zhai R, Cases-Langhoff C, Voss B, Garner AM, Kaempf U, Kindler S, Gundelfinger ED, Garner CC (2000) Piccolo, a presynaptic zinc finger protein structurally related to Bassoon. Neuron 25:203-214.

Fenster SD, Kessels MM, Qualmann B, Chung WJ, Nash J, Gundelfinger ED, Garner CC (2003) Interactions between piccolo and the actin/dynaminbinding protein Abp1 link vesicle endocytosis to presynaptic AZs. J Biol Chem 278:20268-20277.

Frank T, Rutherford MA, Strenzke N, Neef A, Pangrasic T, Khimich D, Fejtova A, Gundelfinger ED, Liberman MC, Harke B, Bryan KE, Lee A, Egner A, Riedel D, Moser T (2010) Bassoon and the synaptic ribbon organize $\mathrm{Ca}^{2+}$ channels and vesicles to add release sites and promote refilling. Neuron 68:724-738.

Frishman LJ (2006) Origins of the electroretinogram. In: Principles and practice of clinical electrophysiology of vision (Heckenlively JR, Arden GB, eds), pp 139-183. London: MIT.

Fuchs M, Brandstätter JH, Regus-Leidig H (2014) Evidence for a clathrinindependent mode of endocytosis at a continuously active sensory synapse. Front Cell Neurosci 8:60.

Guex N, Peitsch MC (1997) SWISS-MODEL and the swiss-PdbViewer: an environment for comparative protein modeling. Electrophoresis 18: $2714-2723$

Gundelfinger ED, Reissner C, Garner CC (2016) Role of Bassoon and piccolo in assembly and molecular organization of the active zone. Front Synaptic Neurosci 7:19.

Harazny J, Scholz M, Buder T, Lausen B, Kremers J (2009) Electrophysiological deficits in the retina of the DBA/2J mouse. Doc Ophthalmol 119: 181-197.

Ivanova D, Dirks A, Montenegro-Venegas C, Schöne C, Altrock WD, Marini C, Frischknecht R, Schanze D, Zenker M, Gundelfinger ED, Fejtova A (2015) Synaptic activity controls localization and function of CtBP1 via binding to Bassoon and piccolo. EMBO J 34:1056-1077.

Ivanova D, Dirks A, Fejtova A (2016) Bassoon and piccolo regulate ubiquitination and link presynaptic molecular dynamics with activity-regulated gene expression. J Physiol 594:5441-5448.

Khimich D, Nouvian R, Pujol R, tom Dieck S, Egner A, Gundelfinger ED, Moser T (2005) Hair cell synaptic ribbons are essential for synchronous auditory signalling. Nature 434:889-894.

Kim S, Ko J, Shin H, Lee JR, Lim C, Han JH, Altrock WD, Garner CC, Gundelfinger ED, Premont RT, Kaang BK, Kim E (2003) The GIT family of proteins forms multimers and associates with the presynaptic cytomatrix protein piccolo. J Biol Chem 278:6291-6300. 
Koipally J, Georgopoulos K (2000) Ikaros interactions with CtBP reveal a repression mechanism that is independent of histone deacetylase activity. J Biol Chem 275:19594-19602.

Lagnado L, Schmitz F (2015) Ribbon synapses and visual processing in the retina. Annu Rev Vis Sci 1:235-262.

Lenzi D, von Gersdorff H (2001) Structure suggests function: the case for synaptic ribbons as exocytotic nanomachines. BioEssays 23:831-840.

Magupalli VG, Schwarz K, Alpadi K, Natarajan S, Seigel GM, Schmitz F (2008) Multiple RIBEYE-RIBEYE interactions create a dynamic scaffold for the formation of synaptic ribbons. J Neurosci 28:7954-7967.

Matthews G, Fuchs P (2010) The diverse roles of ribbon synapses in sensory neurotransmission. Nat Rev Neurosci 11:812-822.

Medrano GA, Manvendra S, Plautz EJ, Good LB, Chapman KM, Chaudhary J, Jaichander P, Powell HM, Pudasaini A, Shelton JM, Richardson JA, Xie XJ, Ivics Z, Braun C, Ackermann F, Garner CC, Izsvák Z, Hamra FK (2018) Mutant Screen Reveals the Piccolo's Control over Depression and Brain-Gonad Crosstalk. bioRxiv. Advance online publication. Retrieved August 31, 2018. doi.org/10.1101/405985

Moser T, Brandt A, Lysakowski A (2006) Hair cell ribbon synapses. Cell Tissue Res 326:347-359.

Mukherjee K, Yang X, Gerber SH, Kwon HB, Ho A, Castillo PE, Liu X, Südhof TC (2010) Piccolo and Bassoon maintain synaptic vesicle clustering without directly participating in vesicle exocytosis. Proc Natl Acad Sci U S A 107:6504-6509.

Nardini M, Spanò S, Cericola C, Pesce A, Massaro A, Millo E, Luini A, Corda D, Bolognesi M (2003) Ctbp/Bars: a dual-function protein involved in transcription co-repression and Golgi membrane fission. EMBO J 22:3122-3130.

Nicolson T (2015) Ribbon synapses in zebrafish hair cells. Hear Res 330:170-177.

Parthier D, Kuner T, Körber C (2018) The presynaptic scaffolding protein piccolo organizes the readily releasable pool at the calyx of held. J Physiol 596:1485-1499.

Pettersen EF, Goddard TD, Huang CC, Couch GS, Greenblatt DM, Meng EC, Ferrin TE (2004) UCSF chimera: a visualization system for exploratory research and analysis. J Comput Chem 25:1605-1612.

Regus-Leidig H, Brandstätter JH (2012) Structure and function of a complex sensory synapse. Acta Physiol 204:479-486.

Regus-Leidig H, Ott C, Löhner M, Atorf J, Fuchs M, Sedmak T, Kremers J, Fejtová A, Gundelfinger ED, Brandstätter JH (2013) Identification and immunocytochemical characterization of Piccolino, a novel piccolo splice variant selectively expressed at sensory ribbon synapses of the eye and ear. PLoS One 8:e70373.

Regus-Leidig H, Fuchs M, Löhner M, Leist SR, Leal-Ortiz S, Chiodo VA, Hauswirth WW, Garner CC, Brandstätter JH (2014) In vivo knockdown of Piccolino disrupts presynaptic ribbon morphology in mouse photoreceptor synapses. Front Cell Neurosci 8:259.

Safieddine S, El-Amraoui A, Petit C (2012) The auditory hair cell ribbon synapse: from assembly to function. Annu Rev Neurosci 35:509-528.

Schmitz F, Königstorfer A, Südhof TC (2000) RIBEYE, a component of syn- aptic ribbons: a protein's journey through evolution provides insight into synaptic ribbon function. Neuron 28:857-872.

Shapira M, Zhai RG, Dresbach T, Bresler T, Torres VI, Gundelfinger ED, Ziv NE, Garner CC (2003) Unitary assembly of presynaptic active zones from piccolo-Bassoon transport vesicles. Neuron 38:237-252.

Sheets L, He XJ, Olt J, Schreck M, Petralia RS, Wang YX, Zhang Q, Beirl A, Nicolson T, Marcotti W, Trapani JG, Kindt KS (2017) Enlargement of ribbons in zebrafish hair cells increases calcium currents, but disrupts afferent spontaneous activity and timing of stimulus onset. J Neurosci 37:6299-6313.

Specht D, Wu SB, Turner P, Dearden P, Koentgen F, Wolfrum U, Maw M, Brandstätter JH, tom Dieck S (2009) Effects of presynaptic mutations on a postsynaptic Cacnals calcium channel colocalized with mGluR6 at mouse photoreceptor ribbon synapses. Invest Ophthalmol Vis Sci 50:505-515.

Terry-Lorenzo RT, Torres VI, Wagh D, Galaz J, Swanson SK, Florens L, Washburn MP, Waites CL, Gundelfinger ED, Reimer RJ, Garner CC (2016) Trio, a Rho family GEF, interacts with the presynaptic active zone proteins Piccolo and Bassoon. PLoS One 11:e0167535.

tom Dieck S, Altrock WD, Kessels MM, Qualmann B, Regus H, Brauner D, Fejtová A, Bracko O, Gundelfinger ED, Brandstätter JH (2005) Molecular dissection of the photoreceptor ribbon synapse: physical interaction of Bassoon and RIBEYE is essential for the assembly of the ribbon complex. J Cell Biol 168:825-836.

tom Dieck S, Specht D, Strenzke N, Hida Y, Krishnamoorthy V, Schmidt KF, Inoue E, Ishizaki H, Tanaka-Okamoto M, Miyoshi J, Hagiwara A, Brandstätter JH, Löwel S, Gollisch T, Ohtsuka T, Moser T (2012) Deletion of the presynaptic scaffold CAST reduces active zone size in rod photoreceptors and impairs visual processing. J Neurosci 32:12192-12203.

Wagh D, Terry-Lorenzo R, Waites CL, Leal-Ortiz SA, Maas C, Reimer RJ, Garner CC (2015) Piccolo directs activity dependent F-actin assembly from presynaptic active zones via Daaml. PLoS One 10:e0120093.

Waites CL, Leal-Ortiz SA, Andlauer TF, Sigrist SJ, Garner CC (2011) Piccolo regulates the dynamic assembly of presynaptic F-actin. J Neurosci 31:14250-14263.

Waites CL, Leal-Ortiz SA, Okerlund N, Dalke H, Fejtova A, Altrock WD, Gundelfinger ED, Garner CC (2013) Bassoon and piccolo maintain synapse integrity by regulating protein ubiquitination and degradation. EMBO J 32:954-969.

Wang X, Kibschull M, Laue MM, Lichte B, Petrasch-Parwez E, Kilimann MW (1999) Aczonin, a $550-\mathrm{kD}$ putative scaffolding protein of presynaptic active zones, shares homology regions with rim and Bassoon and binds profilin. J Cell Biol 147:151-162.

Wichmann C, Moser T (2015) Relating structure and function of inner hair cell ribbon synapses. Cell Tissue Res 361:95-114.

Zanazzi G, Matthews G (2009) The molecular architecture of ribbon presynaptic terminals. Mol Neurobiol 39:130-148.

Zhai RG, Bellen HJ (2004) The architecture of the active zone in presynaptic nerve terminals. Physiology 19:262-270. 